\title{
Best methods for calculating interaction energies in 2-butene and butane systems
}

\author{
Milana M. Zarića ${ }^{a}$, Branko Bugarski ${ }^{\mathrm{b}}$, Mirjana Lj. Kijevčanin ${ }^{\mathrm{b}, *}$ \\ a Institute of Chemistry, Technology and Metallurgy, University of Belgrade, Njegoševa 12, 11000 Belgrade, Serbia \\ ${ }^{\mathrm{b}}$ Faculty of Technology and Metallurgy, University of Belgrade, Karnegijeva 4, 11120 Belgrade, Serbia
}

\section{A R T I C L E I N F O}

\section{Article history:}

Received 19 July 2017

Accepted 1 August 2017

Available online 2 August 2017

\section{Keywords:}

Benchmark

Alkenes

Alkanes

Double bond

$\operatorname{CCSD}(\mathrm{T})$ calculations

DFT calculations

\begin{abstract}
A B S T R A C T
Benchmarking study on eighteen methods, including MP2, B2PLYP-D3, B2PLYP-D3BJ, $\omega B$ 97xD, M05-D3, M06-D3, M052X-D3, M06HF-D3, PBE0-D3, PBE0-D3BJ, B3LYP-D3, B3LYP-D3DJ, TPSS-D3, TPSS-D3BJ, BP86-D3, BP86-D3BJ, BLYP-D3, BLYP-D3BJ and ten basis sets: cc-pVDZ, cc-pVTZ, aug-cc-pVDZ, cc-pVQZ, def2-SVP, def2-TZVP, def2-TZVPP, def2-QZVP, 6-311++G** and 6-31G**, for each method, have been performed, calculating interaction energies in (1) unsaturated/unsaturated systems (2-butene dimers), (2) unsaturated/saturated system (between butane and 2-butene) and (3) saturated/saturated (butane dimers). The calculated interaction energies are compared with accurate $\operatorname{CCSD}(\mathrm{T}) / \mathrm{CBS}$ energies. The data show that most levels of theory have the highest errors for systems with butane dimers, and calculated interaction energies in these systems are overestimated. The best levels, overall for all systems, are BLYP-D3BJ/def2-QZVP and BLYP-D3BJ/cc-pVQZ with similar root mean square deviation (RMSD) values of $0.056 \mathrm{kcal} \mathrm{mol}^{-1}$ and $0.060 \mathrm{kcalmol}^{-1}$ compared to $\operatorname{CCSD}(\mathrm{T})$ values. The best level for (1) 2-butene dimers is B3LYP-D3BJ/aug-cc-pVDZ; for (2) interactions between 2-butene and butane is BLYP-D3BJ/def2-SVP; while for (3) butane dimers is BLYP-D3BJ/def2-QZVP. The differences in calculated energies among several methods are not high, however, it is important that most of the DFT methods overestimate interactions in butane dimers.
\end{abstract}

(C) 2017 Elsevier B.V. All rights reserved.

\section{Introduction}

Properties of molecules with double bonds show usually high electron densities and large polarizabilities, that cause electrostatic and dispersion dominated non-covalent interactions. It is one of the reasons that non-covalent interactions of molecules with $\pi$ bonds are attractive to study [1-22]. Interactions of aromatic molecules were often studied as models for interactions of $\pi$-systems $[1,2,7,8,23]$. In addition, interactions of ethene (ethylene) have been studied as systems for interactions of molecules with double bonds [11-22]. Differences in behavior between saturated molecules and unsaturated molecules with double bonds, as well as differences between unsaturated molecules with cis- and transdouble bonds are of great importance in various molecular systems and processes [24-28]. Properties of cis- and trans- isomers may differ and best examples are cis- and trans- unsaturated fatty acids. The shapes of molecules are defined by the configuration of molecule and therefore it effects their ability to pack. The cis-configuration is rigid with less freedom of bending, hence molecules of

\footnotetext{
* Corresponding author.

E-mail address: mirjana@tmf.bg.ac.rs (M.Lj. Kijevčanin).
}

cis-fatty acids have lower ability to pack close. On the other hand, trans-configuration enables fatty acids to pack close, influencing blood vessels and trans-fatty acids raise risk for heart disease and affects cardiovascular health [28]. For 2-butene, trans-configuration is more stable than cis-configuration, while the explanation of these relative stabilities is still a controversial. In recent work detailed study on the stability of cis- and trans-2-butene isomers was performed, showing that significant influence on stability of isomers have middle part of the 2-butene molecule [29].

The simplest model system of unsaturated molecules with cis- and trans-double bonds is 2-butene molecule. In our previous study, we have studied the non-covalent interactions of cis- and trans-2-butene, as well as interactions of butane, as systems with saturated bonds [30]. Various contributions to the interaction energies were analyzed performing the Symmetry-Adapted Perturbation Theory (SAPT) decomposition analysis [31]. The analysis indicate that for an interaction in each system dispersion is the largest contribution to the total energy. Comparison of the dispersion in various systems show that the dispersion is the largest in 2-butene/butane systems, followed by 2-butene/2-butene systems, while it is the weakest in butane/butane systems. The electrostatic is attractive in all calculated systems; it is the strongest in 
2-butene/butane systems, while in butane/butane systems is the weakest. At the same time, the repulsion is also the strongest in 2-butene/butane systems and the weakest in butane/butane systems [30]. These data indicate that existence of double bonds increases dispersion and electrostatic, but also increases the repulsion.

Several benchmark studies were performed on accuracy of various DFT and MP2 methods for non-covalent interactions of alkanes [32-36]. A study on 1200 chemically varied gas phase dimers, including alkane dimers, showed that, generally, DFT-D methods give interaction energies with accuracy of $1.0 \mathrm{kcal} \mathrm{mol}^{-1}$ [32]. The results also indicated, as can be anticipated, that DFT methods without dispersion correction underestimate interaction energies. The dispersion correction is not equally important for all DFT methods; it is, for example, very important for B3LYP method [32]. Studies on unbranched alkane dimers showed linear correlation of calculated interaction energies at MP2 and DFT-D methods with experimental heats of vaporization and critical temperatures [33] and good performance of semi-local MGGA density functional in comparison to DFT-D methods [34]. DFT-D methods overestimate interaction energies, while the error is high for longer alkanes. For most of the methods, the error increases with increasing size of basis set. However, the calculations with DFT-D methods showed that increase of basis set does not lead to increased interaction energies for all DTF-D methods [33].

In our previous work, only interaction energies in cis-2-butene dimers obtained with MP2 and several DFT methods, were compared to $\operatorname{CCSD}(\mathrm{T}) / \mathrm{CBS}$ values [30], and the results at M052X-D3/ cc-pVDZ level were in the best agreement with $\operatorname{CCSD}(\mathrm{T}) / \mathrm{CBS}$ energies. As the SAPT analysis indicate somewhat different nature of interactions in three systems (1) unsaturated/unsaturated, (2) unsaturated/saturated, and (3) saturated/saturated systems [30], one can assume that different DFT methods would be best for the each of the particular systems. Our aim was to find the best methods for these various systems and to check differences in accuracy for list of several good performing methods. These results can show if it is necessary to use different methods for systems with saturated and double bonds, or it is acceptable to use the same method for all systems. Hence, in this work we performed detailed benchmark study using MP2 and seventeen DFT-D methods, with ten basis sets, which makes 180 levels of theory on all possible parallel interactions in (1) 2-butene dimers, between (2) butane and 2-butene, and in (3) butane dimers. To the best of our knowledge benchmark study on these systems have not been published so far. Our results show difference in performance of used methods for systems with double and single bonds.

\section{Methods}

We have studied interactions in ten model systems with 2-butene and butane molecules where monomers have parallel orientation and, also, middle bonds (double or single) are always oriented parallel. For the calculations we used Gaussian09 (version D.01) [37].

The detailed benchmark study of 180 level of theory was performed, using eighteen methods: MP2 [38], BLYP-D3 [39], BLYP-D3BJ [39], BP86-D3 [40], BP86-D3BJ [40] M05-D3 [41], M052X-D3 [42], M06-D3 [43], M06HF-D3 [44], TPSS-D3 [45], TPSS-D3BJ [45], PBE0-D3 [46], PBE0-D3BJ [46], B3LYP-D3 [47], B3LYP-D3DJ [47], B2PLYP-D3 [48], B2PLYP-D3B] [48], $\omega B 97 x D$ [49], and ten basis set: Dunning's correlation consistent basis sets (cc-pVDZ [50], cc-pVTZ [51], cc-pVQZ [52], aug-cc-pVDZ [52]), basis sets of Ahlrichs and coworkers [53] (def2-SVP, def2-TZVP, def2-TZVPP, def2-QZVP) and Pople basis sets (6-31G** [54] and $\left.6-311++G^{* *}[55]\right)$. In each type we used the basis sets of various sizes, in order to evaluate influence of the size and the type of the basis set on the accuracy of the results. In this study $a b$ initio MP2 method and list of DFT methods have been used, as the DFT methods are the most often methods for computational study of non-covalent interactions, especially since great progress had been made to include the dispersion interactions. We investigated the next list of the DFT methods, the GGA functionals: BP86 and BLYP; the meta-GGA functional: TPSS; the hybrid-GGA: B3LYP, PBE0; the hybrid meta-GGA: MO6, M05, M06HF, and M052X; and the double hybrid GGA functional: B2PLYP. All these methods were used with D3 Grimme's dispersion correction [56]. For some methods the version with Becke-Johnson damping functions was available and it was implemented [57]. These two dispersion corrections, DFTD3 and DFT-D3BJ, were used, since they give good results for non-covalent interactions [58].

The basis set superposition error correction was applied to all interaction energies [59]. Calculated interaction energies were compared with the $\operatorname{CSD}(\mathrm{T}) / \mathrm{CBS}$ values for all possible parallel interactions in 2-butene dimers, between butane and 2-butene, and in butane dimers. The method suggested by Mackie and DiLabio was performed for calculations on interaction energies at $\operatorname{CCSD}(\mathrm{T}) / \mathrm{CBS}$ level [60]. The method calculates average values of energies corrected and uncorrected for basis set superposition error [59]. The MP2/CBS energies were estimated using average values of basis sets aug-cc-pVDZ [50-52], aug-cc-pVTZ [51,52] and aug-cc-pVQZ [51,52]. Starting from the assumption that the difference in $\operatorname{CCSD}(\mathrm{T}) / \mathrm{CBS}$ and $\operatorname{CCSD}(\mathrm{T}) /$ aug-cc-pVDZ binding energies is similar to the difference in MP2/CBS and MP2/aug-cc-pVDZ [60] the values of $\operatorname{CCSD}(\mathrm{T}) / \mathrm{CBS}$ are estimated.

Two geometric parameters, normal distance, $R$, and parallel displacement (offset) $r$, are used to describe geometries and they are given in Fig. 1. The length between the planes of the two molecules is defined as normal distance, $R$. The length between center of middle bond of one molecule and its projection on the plane of the center of middle bond on the other molecule is defined as parallel displacement (offset) $r$. The potential energy surfaces were made by calculating the interaction energies, for parallel orientations, as a function of the horizontal displacements (offsets $r$ ) in a single point series calculations by varying the normal distance $(R)$ between molecules.

\section{Results and discussion}

In this work we performed detailed benchmark study using 180 levels of theory (eighteen methods and ten basis sets); the list of the methods and basis sets is given in the Methodology section.

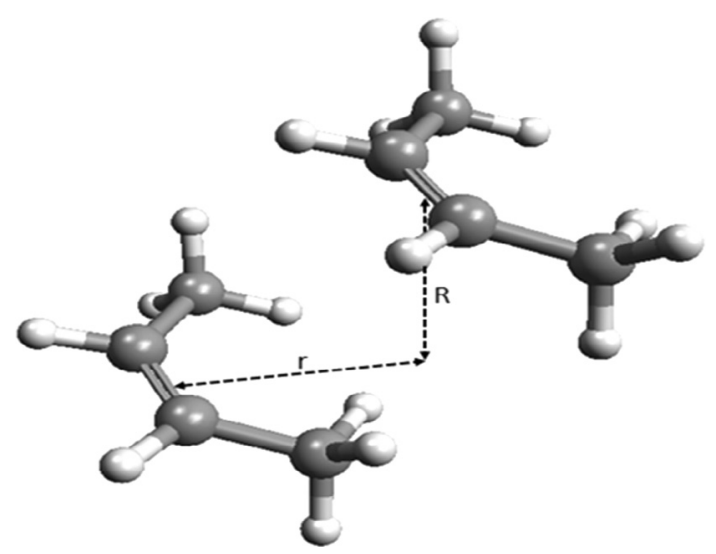

Fig. 1. Model system of cis-2-butene dimers showing normal distance, $R$ and parallel displacement (offset), $r$. 
The calculated interaction energies were compared with the CCSD (T)/CBS energies. The calculations were performed on (1) unsaturated/unsaturated systems (2-butene dimers), (2) unsaturated/saturated systems (2-butene/butane) and (3) saturated/saturated systems (butane dimers) (Figs. 2, 4, 6). Data on each system are discussed in separate sections below. The geometries used for the calculations in this work are minima on potential energy surfaces that were obtained in previous work [30].

\section{1. (1) 2-butene dimer model systems}

There are five geometries for (1) unsaturated/unsaturated systems, 2-butene dimers: parallel and antiparallel orientation of cis-2-butene and trans-2-butene dimers, and one for cis- and trans-2-butenes interaction (Fig. 2). For these systems the list of the best levels with the calculated root mean square deviation (RMSD), the mean error (ME), the mean absolute error (MAE), the mean absolute relative error (MARE), and the standard deviation (SD) of calculated energies compared to the $\operatorname{CSD}(\mathrm{T})$ are given in Table 1. Fig. 3 presents the MARE and the ME data for all levels of theory used in this study. The RMSD values, the ME, the MAE, the MARE and the SD values for set of 180 levels are given in Table S1 in Supporting Information. The best level for 2-butene dimers is B3LYP-D3BJ/aug-cc-pVDZ with RMSD error of $0.020 \mathrm{kcal} \mathrm{mol}^{-1}$ and with MARE less than $1 \%(0.66 \%)$ and SD of $0.020 \mathrm{kcal} \mathrm{mol}^{-1}$. Moreover, data in Table 1 show that several other levels have similar errors and standard deviations, like B3LYP-D3BJ/cc-pVTZ, and B2PLYP-D3/def2-QZVP with RMSD errors of $0.023 \mathrm{kcal} \mathrm{mol}^{-1}$. All levels presented in Table 1 have RMSD below $0.05 \mathrm{kcal} \mathrm{mol}^{-1}$, MARE lower than $1.1 \%$, and SD lower than $0.04 \mathrm{kcal} \mathrm{mol}^{-1}$.

For the five model systems (1) with 2-butene dimers, from the 180 levels used in this study there are 48 (27\%) theory levels that have calculated RMSD errors below $0.100 \mathrm{kcal} \mathrm{mol}^{-1}$ (Supplementary Information S5). Almost all energies calculated with B3LYPD3BJ, B3LYP-D3 and PBE0-D3 methods have the RMSD error below $0.100 \mathrm{kcal} \mathrm{mol}^{-1}$, independent of the used basis set.

Considering each of the 2-butene dimer model system separately, there are 900 calculated energies, 180 levels for each of the five model system. From these 900, 331 energies have errors below $0.100 \mathrm{kcal} \mathrm{mol}^{-1}$, which is $36 \%$. For each method we calculated 50 energies, namely, five systems calculated with ten different basis sets. The method with most errors below $0.100 \mathrm{kcal} \mathrm{mol}^{-1}$ is B3LYP-D3BJ with 40 energies of 50 (80\%), followed by B3LYP-D3 with 38 energies (76\%), PBE0-D3 with 37 (74\%), TPSS-D3 with 35 (70\%) and PBE0-D3BJ with 32 (64\%). There are 4 methods, M05, M06, M06HF, B2PLYP-D3BJ, with less than $10 \%$ calculated energies with good agreement with $\operatorname{CCSD}(\mathrm{T})$ values (errors less than $0.100 \mathrm{kcal} \mathrm{mol}^{-1}$ ). Only one method, M06 have none of errors below the value of $0.100 \mathrm{kcal} \mathrm{mol}^{-1}$.

Fig. 3a presents the mean absolute relative error (MARE) in \% for every method with each basis set. In Fig. 3b are mean errors (ME), that show if calculated energies are underestimated or overestimated in respect to the $\operatorname{CCSD}(\mathrm{T}) / \mathrm{CBS}$ values. As data in Table 1 , the data in Fig. 3, show that B3LYP method, both with D3 and $\mathrm{D} 3 \mathrm{BJ}$ dispersion corrections gives results in very good agreement with $\operatorname{CCSD}(\mathrm{T}) / \mathrm{CBS}$ values, with almost all used basis sets.

The data in Fig. 3 show that the basis set has the largest influence on the MP2 method, while for most of the DFT methods, basis sets do not have significant influence on most of the calculated energies, with exception of M06-D3, M06HF-D3, B2PLYP-D3, and B2PLYP-D3BJ. The increase in basis set size improves results with MP2 method; MP2 method with the largest basis sets (aug-ccpVDZ, cc-pVQZ, and def2-QZVP) gives the best results. Although for DFT methods B2PLYP and M06 the influence of basis sets is smaller than for MP2 method, it is still significant. The B2PLYPD3 method gives the best results with the largest basis sets (def2-QZVP, cc-pVQZ, aug-cc-pVDZ, def2-TZVPP), while B2PLYP$\mathrm{D} 3 \mathrm{BJ}$ overestimates interaction energies in 2-butene dimers with large basis sets (Fig. $3 \mathrm{~b}$ ) and gives the best results with $6-311+$ $+G^{* *}$ basis set. The M06-D3 method overestimates energies, and the best results are with small basis sets, cc-PVDZ and def2-SVP. For M06HF-D3 method some basis sets overestimate, while most of them underestimate energies, and different basis sets give the best results for different model system (Supporting Information Table S1). The basis sets do not have significant influence for other DFT methods, especially low influence, and very similar energies for all basis sets, are for TPSS-D3, BP86-D3, BLYP-D3BJ, B3LYP and PBE0 (last two methods with both corrections D3 and D3BJ,

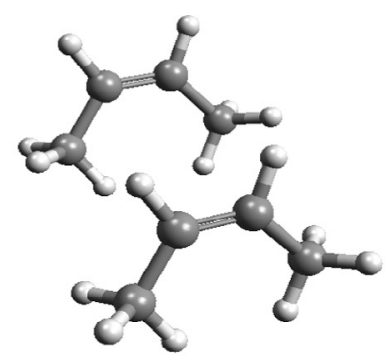

(a)

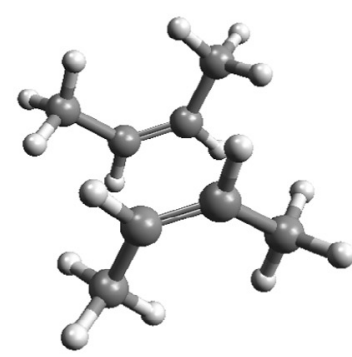

(b)

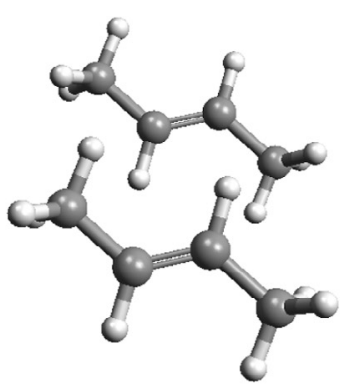

(c)

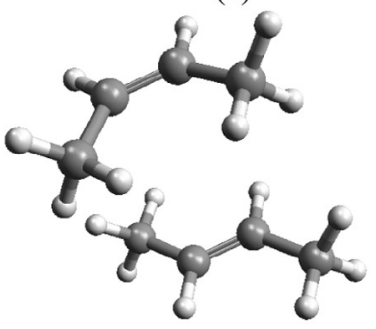

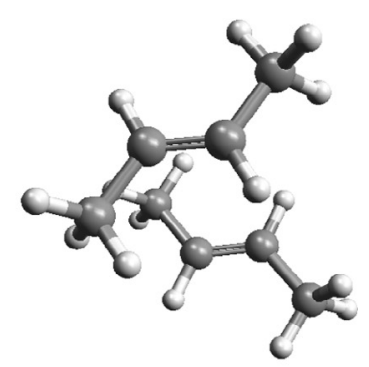

(d)

(e)

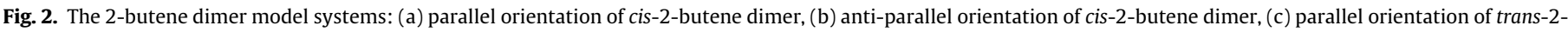
butene dimer, (d) anti-parallel orientation of trans-2-butene dimer, (e) cis-2-butene/trans-2-butene. 
Table 1

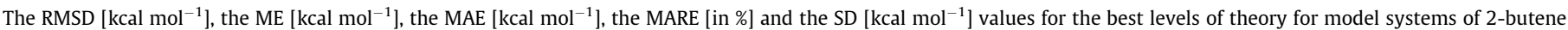
dimers.

\begin{tabular}{|c|c|c|c|c|c|c|c|}
\hline & Method & Basis set & RMSD & ME & MAE & MARE & SD \\
\hline 1 & B3LYP-D3BJ & aug-cc-pVDZ & 0.020 & 0.007 & 0.016 & 0.66 & 0.020 \\
\hline 2 & B3LYP-D3BJ & cc-pVTZ & 0.023 & -0.011 & 0.021 & 0.96 & 0.023 \\
\hline 3 & B2PLYP-D3 & def2-QZVP & 0.023 & 0.001 & 0.020 & 0.91 & 0.026 \\
\hline 4 & B3LYP-D3BJ & def2-TZVP & 0.026 & 0.011 & 0.021 & 0.94 & 0.026 \\
\hline 5 & B2PLYP-D3 & cc-pVQZ & 0.027 & 0.015 & 0.022 & 0.98 & 0.024 \\
\hline 6 & PBE0-D3BJ & def2-QZVP & 0.032 & 0.007 & 0.024 & 1.02 & 0.035 \\
\hline 7 & B3LYP-D3 & def2-TZVPP & 0.037 & -0.015 & 0.031 & 1.35 & 0.038 \\
\hline 8 & B3LYP-D3 & cc-pVTZ & 0.039 & 0.005 & 0.032 & 1.39 & 0.043 \\
\hline 9 & B3LYP-D3BJ & def2-TZVPP & 0.039 & -0.031 & 0.034 & 1.60 & 0.027 \\
\hline 10 & PBE0-D3BJ & cc-pVQZ & 0.040 & 0.021 & 0.026 & 1.07 & 0.037 \\
\hline
\end{tabular}

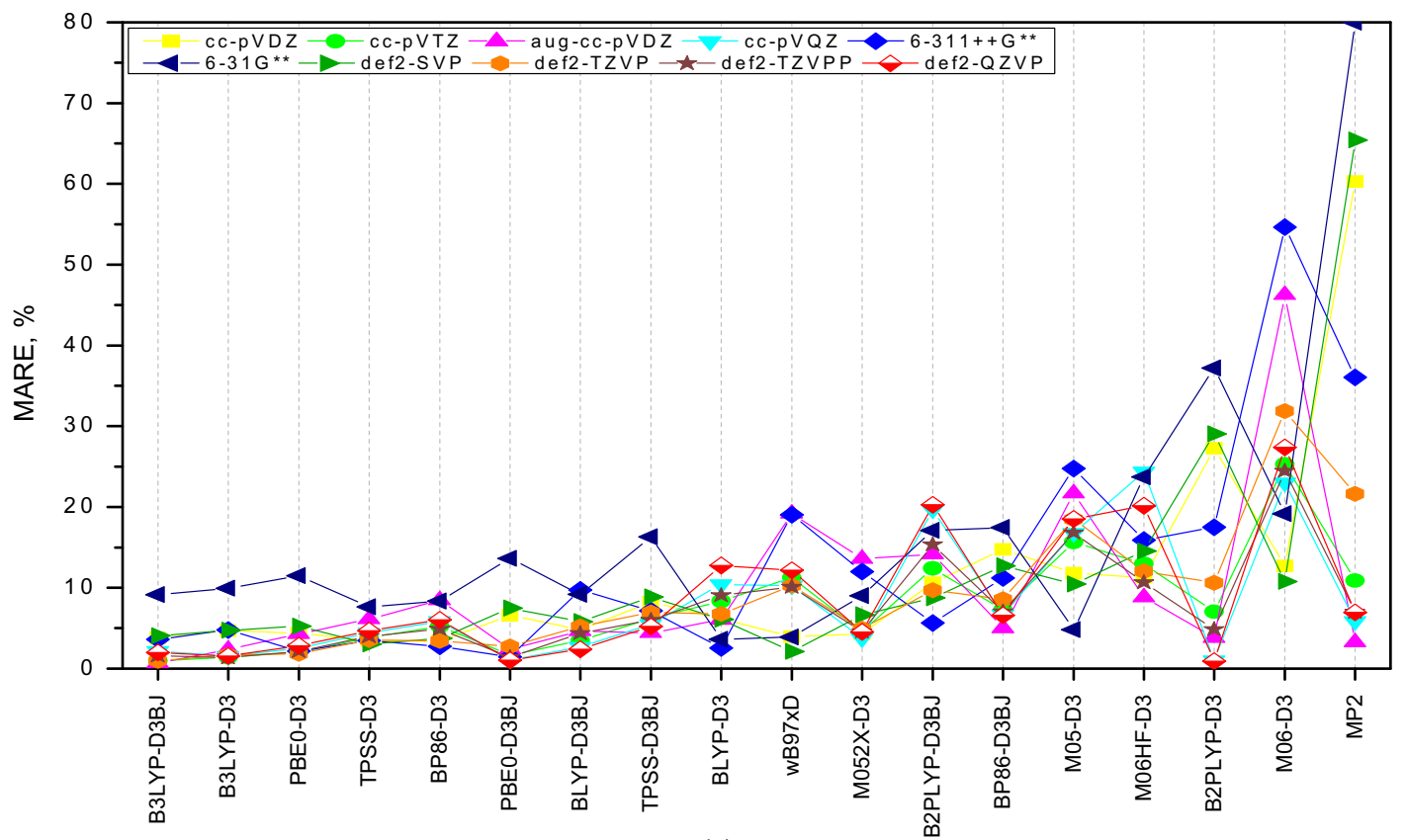

(a)

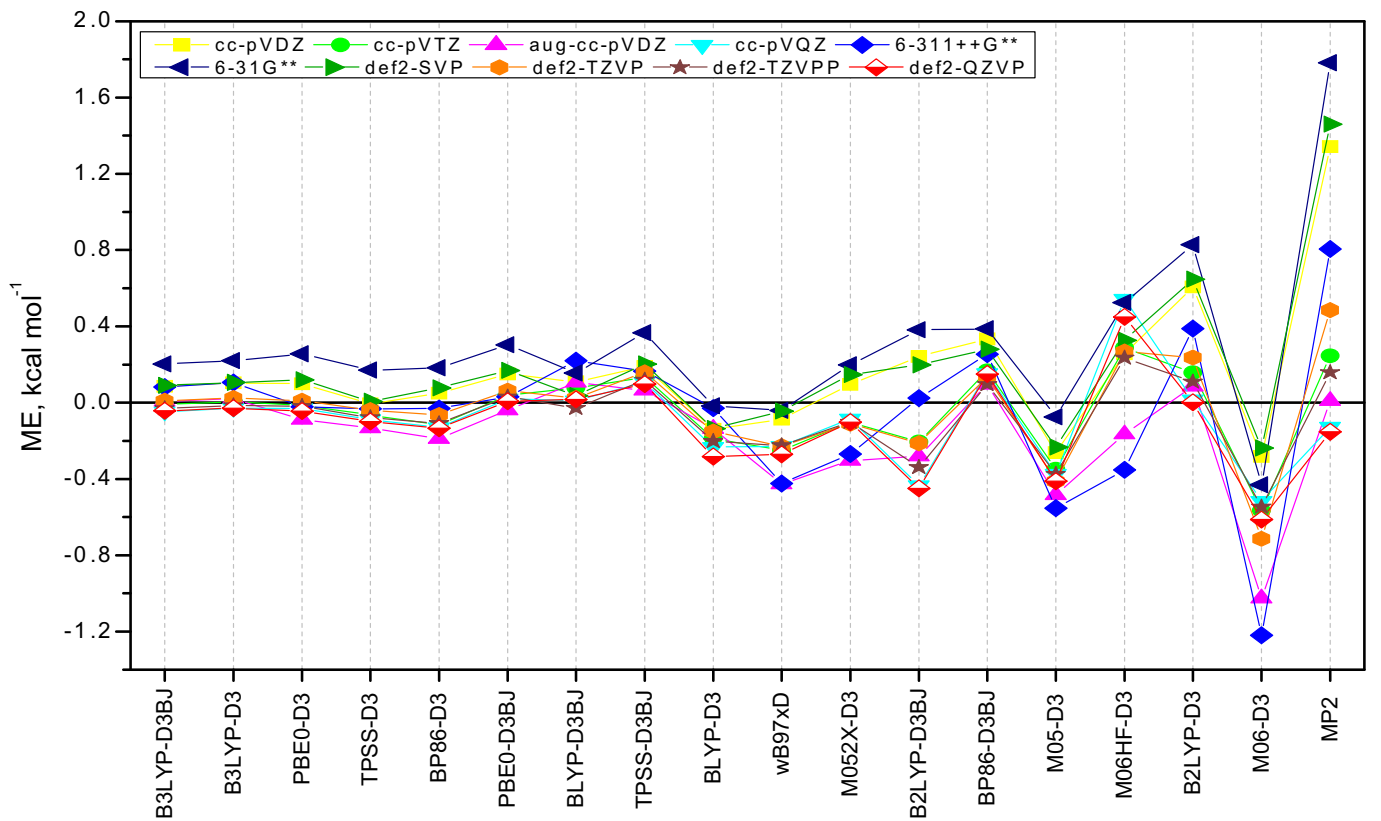

(b)

Fig. 3. (a) Mean Absolute Relative Error (MARE) [\%], (b) Mean Error (ME) [kcal mol ${ }^{-1}$ ] for 2-butene dimers. 
with exception of one basis set, 6-31G**). All these methods, with almost all basis sets are in very good agreement with $\operatorname{CCSD}(\mathrm{T}) /$ CBS energies. One can observe that basis set $6-31 G^{* *}$ gives low agreement with high number of the methods (Fig. 3a), energies calculated with this basis set are the most underestimated (Fig. 3b).

Data in Table 1 show that six of ten best levels are with D3BJ correction. Data in Fig. 3 indicate similar; most of the methods, independent of basis sets give similar accuracy with D3 and D3BJ corrections, with exceptions of BP86 that is better with D3 correction, and BLYP and B2PLYP that are better with D3BJ corrections.

\section{2. (2) 2-butene/butane model systems}

For (2) unsaturated/saturated systems there are three geometries that represent interactions between 2-butene and butane: one for cis-2-butene/butane and two for trans-2-butene/butane, parallel and anti-parallel orientation (Fig. 4).

The list of the best levels for 2-butene/butane systems is given in Table 2, while Fig. 5 presents data for all levels of theory used in this study. Similar to the data for 2-butene dimer (Table 1) several levels of theory have similar errors; the best level is BLYP-D3BJ/ def2-SVP (with RMSD error of $0.023 \mathrm{kcal} \mathrm{mol}^{-1}$, MARE of $0.74 \%$, and SD of $0.017 \mathrm{kcal} \mathrm{mol}^{-1}$ ), closely followed with three other levels (Table 2). The ten best levels that are given in Table 2 have RMSD values below $0.05 \mathrm{kcal} \mathrm{mol}^{-1}$, MARE less than $2.3 \%$ and SD lower than $0.04 \mathrm{kcal} \mathrm{mol}^{-1}$. The 28 levels (16\% from 180) have RMSD values below $0.100 \mathrm{kcal} \mathrm{mol}^{-1}$; it is lower number than above mentioned for 2-butene dimers, 48 levels. The RMSD values, the ME, the MAE, the MARE and the SD values for 180 levels are given in Table S2 (Supporting Information), while in Table S5 (Supporting Information) is the list of levels that have the RMSD values below $0.100 \mathrm{kcal} \mathrm{mol}^{-1}$. The BLYP-D3BJ method has RMSD values less than $0.100 \mathrm{kcal} \mathrm{mol}^{-1}$ for all basis set except for $6-311++\mathrm{G}^{* *}$.

Considering each of three 2-butene/butane model system (Fig. 4) separately, we have 540 energies (180 levels applied on three model systems). Of these 540 energies, 115 (21\%) have errors below $0.100 \mathrm{kcal} \mathrm{mol}^{-1}$. For each method, 30 energies are calculated (10 different basis sets for each of the three model systems). The best method is BLYP-D3BJ since $90 \%$ of calculated energies ( 27 of 30) have the RMSD errors below $0.100 \mathrm{kcal} \mathrm{mol}^{-1}$. The next best method is PBE0-D3BJ with 15 (50\%) energies, followed by B3LYPD3BJ and TPSS-D3BJ with 13 energies (43\%), M06HFand B2PLYPD3BJ with 11 energies, and BP86-D3BJ with 9 energies (30\%). There are eight methods, BLYP-D3, BP86-D3, M05, M06, TPSS-D3, PBE0D3, B3LYP-D3 and $\omega$ B97xD that have less than $10 \%$ energies with errors below than $0.100 \mathrm{kcal} \mathrm{mol}^{-1}$.

As was mentioned above, for 2-butene/butane system, BLYP method, with $\mathrm{D} 3 \mathrm{BJ}$ dispersion correction, gives results in very good agreement with $\operatorname{CCSD}(\mathrm{T}) / \mathrm{CBS}$ values, with almost all used basis sets (Fig. 5). On the other hand, BLYP method with D3 correction overestimates calculated energies with all basis sets. Several methods with D3BJ dispersion corrections give very good agreement with $\operatorname{CCSD}(\mathrm{T}) / \mathrm{CBS}$ values (Fig. 5), while among ten best levels of theory, eight have D3BJ corrections. The data in Fig. 5 indicate that for all method were D3BJ correction is available, data are better with D3BJ than with D3 correction, except for D2PLYP where accuracy is very similar.

Similar to the results for 2-butene dimers (Fig. 3), for 2-butene/ butane systems basis set has the highest influence on MP2 method, while for most of DFT methods, basis sets do not have significant influence on calculated energies, with exception of M06, B2PLYP and M06HF (Fig. 5). The increase in basis set size improves results with MP2 method; the largest basis sets (cc-pVQZ, def2-QZVP, augcc-pVDZ) give the best results. Similar to the 2-butene dimer (Fig. 3), B2PLYP-D3 method gives the best results with relatively large basis sets (cc-pVTZ, def2-TZVPP, and def2-TZVP) (Fig. 5), while B2PLYP-D3BJ overestimate interaction energies with large basis sets and gives the best results with cc-pVDZ and def2-SVP basis sets. M06-D3 method significantly overestimates energies, and the best results are with small basis sets. For M06HF-D3

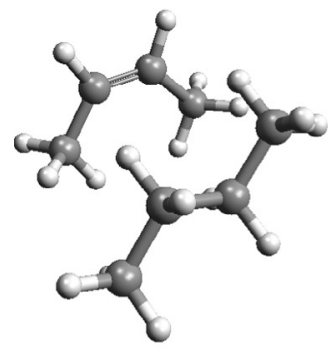

(a)

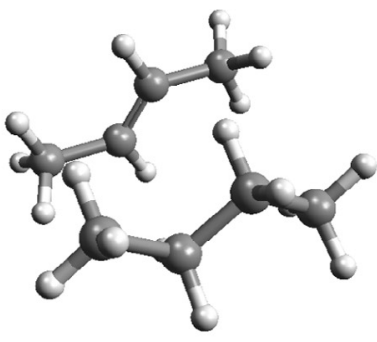

(b)

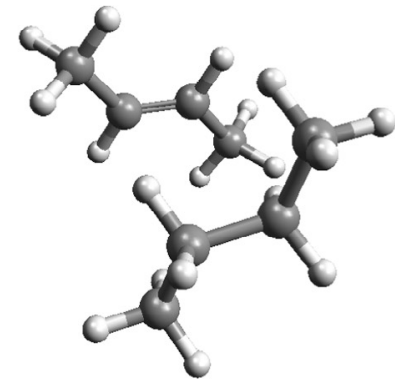

(c)

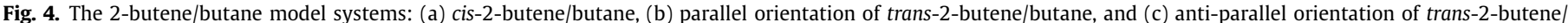
butane.

Table 2

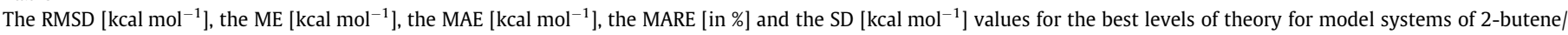
butane.

\begin{tabular}{|c|c|c|c|c|c|c|c|}
\hline & Method & Basis set & RMSD & ME & MAE & MARE & SD \\
\hline 1 & BLYP-D3BJ & def2-SVP & 0.023 & -0.018 & 0.019 & 0.74 & 0.017 \\
\hline 2 & B3LYP-D3BJ & $6-31 G^{* *}$ & 0.025 & -0.015 & 0.023 & 0.85 & 0.024 \\
\hline 3 & BLYP-D3BJ & aug-cc-pVDZ & 0.027 & 0.025 & 0.025 & 0.92 & 0.013 \\
\hline 4 & BLYP-D3BJ & cc-pVDZ & 0.027 & -0.022 & 0.023 & 0.86 & 0.020 \\
\hline 5 & PBE0-D3BJ & $6-31 G^{* *}$ & 0.032 & 0.0083 & 0.026 & 0.95 & 0.037 \\
\hline 6 & M06HF-D3 & def2-TZVPP & 0.036 & 0.022 & 0.022 & 0.79 & 0.036 \\
\hline 7 & M06HF-D3 & def2-TZVP & 0.038 & -0.0017 & 0.031 & 1.20 & 0.046 \\
\hline 8 & BLYP-D3BJ & def2-TZVP & 0.038 & 0.018 & 0.031 & 1.2 & 0.041 \\
\hline 9 & PBE0-D3BJ & def2-SVP & 0.039 & -0.008 & 0.036 & 1.4 & 0.046 \\
\hline 10 & BLYP-D3BJ & cc-pVTZ & 0.040 & -0.032 & 0.033 & 1.26 & 0.031 \\
\hline
\end{tabular}


method some basis sets overestimate, while most of them give quite good results; the results with def2-TZVPP and def2-TZVP are in excellent agreement with $\operatorname{CCSD}(\mathrm{T}) / \mathrm{CBS}$ values (Table 2).

As was mentioned above, for most of the DFT methods basis sets do not have significant influence. Several methods slightly overestimate interaction energies, PBE0 and B3LYP (with both D3 and D3BJ corrections; although the results with D3BJ correction are better), TPSS-D3, and BP86-D3; M052X-D3, $\omega B$ 97xD-D2, BLYP-D3, and M05-D3 methods overestimate it significantly, while two methods, TPSS and BP86, with D3BJ corrections, slightly underestimate energies. The BLYP-D3BJ method, with almost all basis sets, give results in very good agreement with $\operatorname{CCSD}(\mathrm{T}) / \mathrm{CBS}$ data, moreover five of ten is among the best methods for 2-butene/butane model systems (Table 2), as was mentioned above. One can notice that for almost all methods, similar to 2-butene dimer systems, with small basis sets $6-31 G^{* *}$, $6-311++G^{* *}$ and def2-SVP the calculated energies are the weakest (Fig. 5). Differently than in case of 2-butene systems, since number of methods overestimate interaction energies, the errors are the smallest for these small basis sets.

\section{3. (3) Butane dimer systems}

Interactions in (3) saturated/saturated systems in butane dimers, are represented with two orientations, parallel and antiparallel (Fig. 6). The data in Fig. 7 and Table 3, as well as data

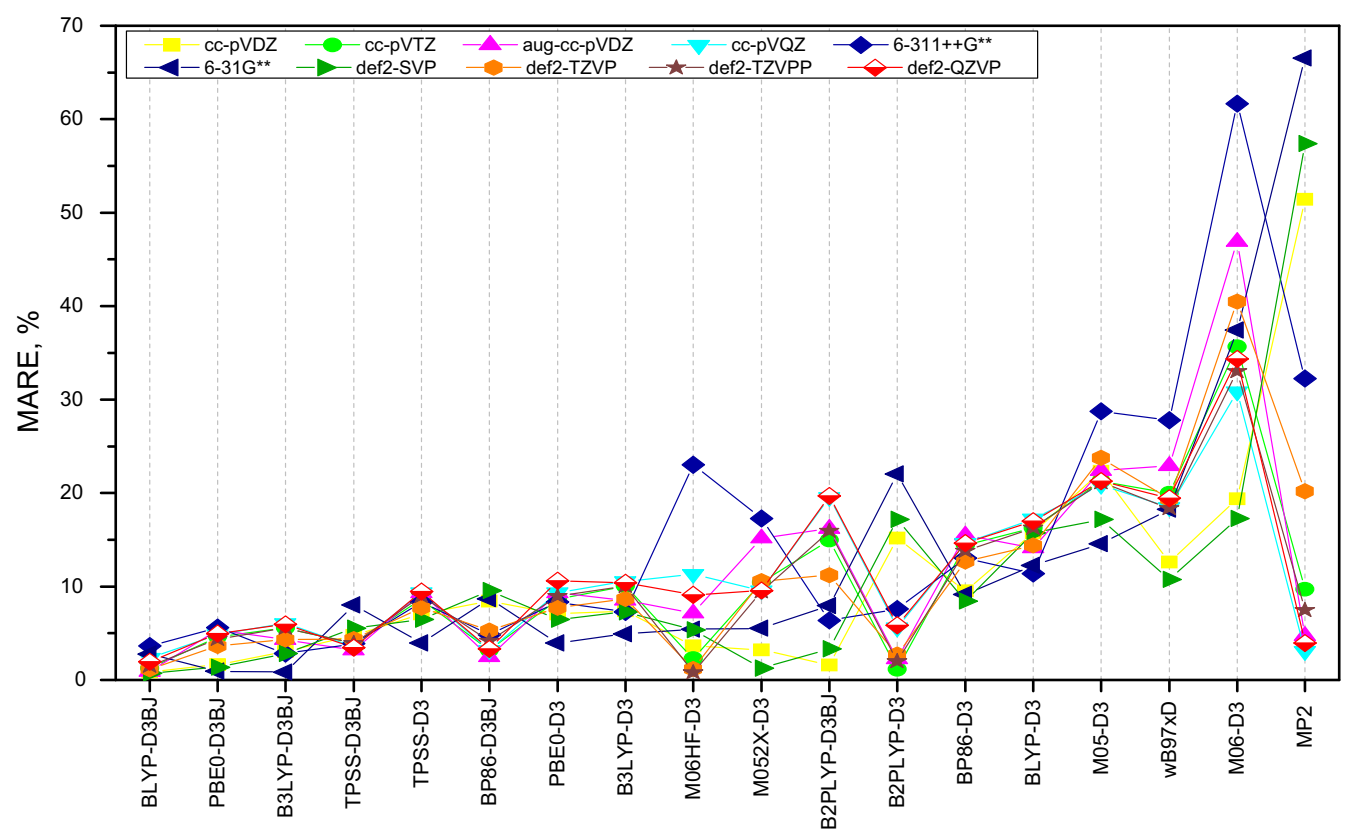

(a)

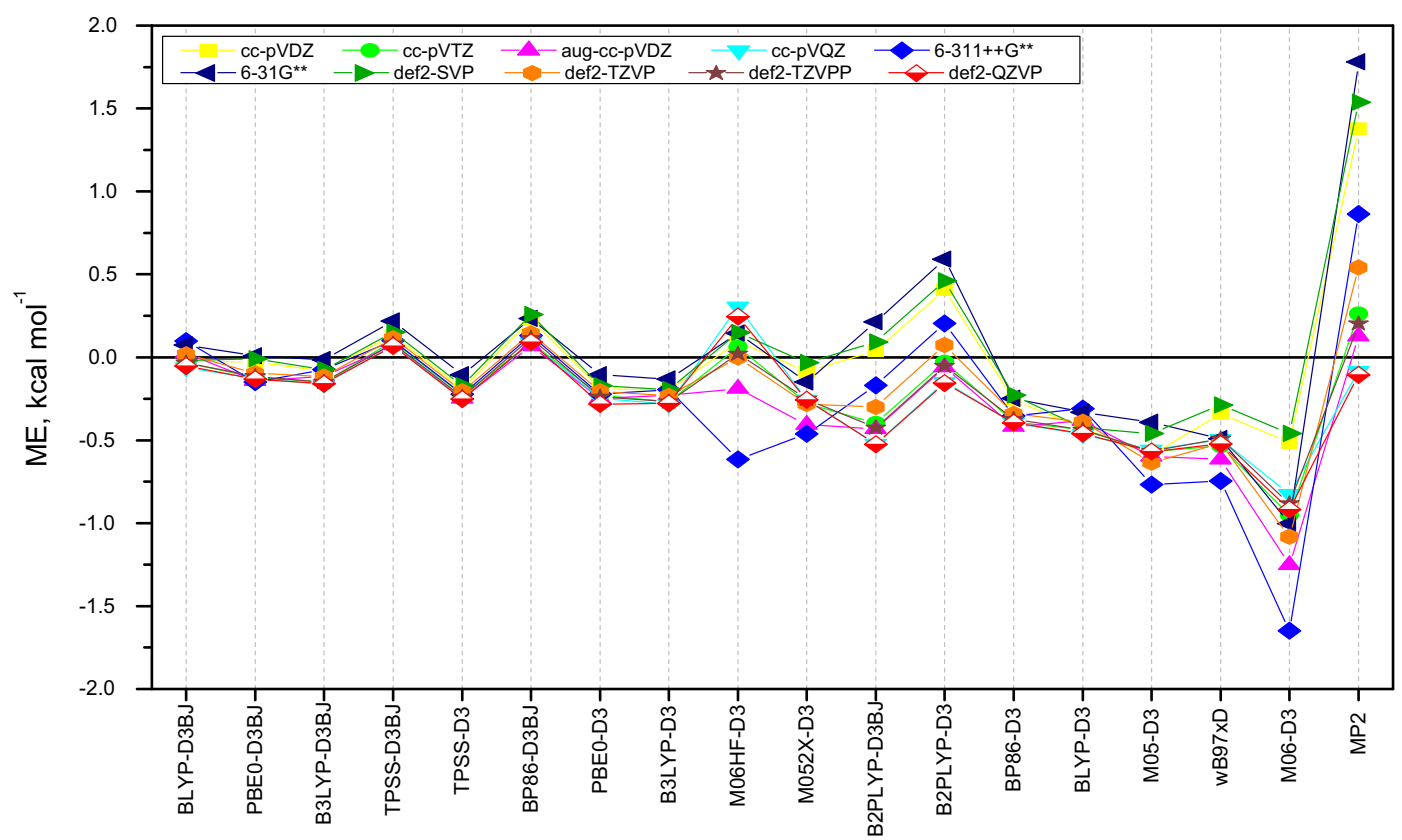

(b)

Fig. 5. (a) Mean Absolute Relative Error (MARE) [\%], (b) Mean Error (ME) [kcal mol ${ }^{-1}$ ] for 2-butene/butane 


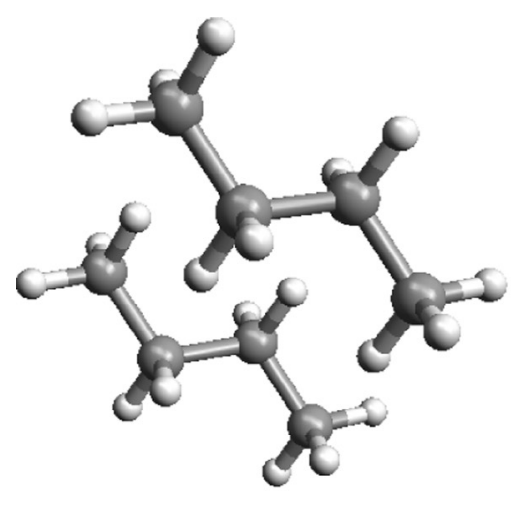

(a)

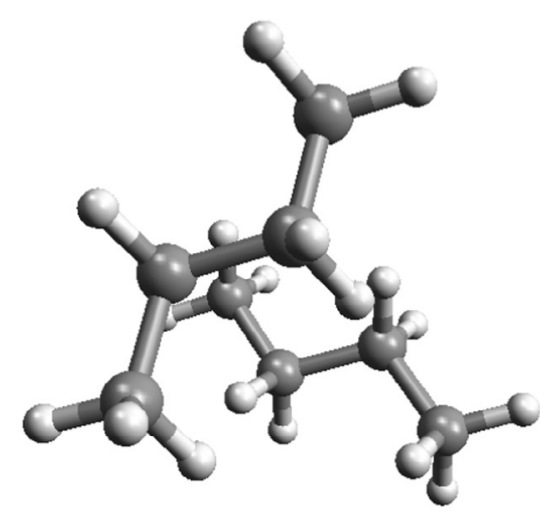

(b)

Fig. 6. The butane dimer model systems: (a) parallel orientation, (b) anti-parallel orientation.

in Supporting Information Table S3 show that small number of levels are in good agreement with $\operatorname{CCSD}(\mathrm{T}) / \mathrm{CBS}$ values for butane dimers, differently than in cases of 2-butene dimers and 2-butene/butane systems (Tables 1 and 2 and S1 and S2 in Supporting Information). The RMSD values, the ME, the MAE, the MARE and the SD values for set of 360 levels (180 levels applied on two model systems) are given in Table S3 in Supporting Information. In Table S5 in Supplementary Information represent the two model systems parallel and antiparallel butane dimer that have calculated RMSD errors below $0.100 \mathrm{kcal} \mathrm{mol}^{-1}$. The most important about interaction energies in butane dimer system is that most of the methods, independently of the basis sets, significantly are overestimated (Fig. 7b).

The best level for butane dimer system is BLYP-D3BJ/def2-QZVP with the RMSD error of $0.004 \mathrm{kcal} \mathrm{mol}^{-1}$, MARE of $0.1 \%$, and SD of $0.035 \mathrm{kcal} \mathrm{mol}^{-1}$. There are eight levels from $180(4 \%)$ that have RMSD values below $0.100 \mathrm{kcal} \mathrm{mol}^{-1}$; much smaller number than in cases of 2-butene dimers and 2-butene/butane, 48 and 28 levels, respectively. The best agreements show BLYP-D3BJ, TPSS-D3BJ and MP2 methods with large def2-QZVP and cc-pVQZ basis sets. Only three levels have MARE below 1\%, while the tenth level for butane dimer have MARE close to 5\% (Table 3), indicating that errors for butane dimer are the highest among the thee model systems (1) 2-butene dimers, (2) 2-butene/butane, and (3) butane dimers.

In Supporting Information, Table S3, shows the RMSD, the ME, the MAE, the MARE and the SD values for butane dimers. Data indicate that all DFT methods with D3BJ correction available, give better results with D3BJ correction, than with D3 correction, with exception of B2PLYP where results are somewhat better for D3 correction (Fig. 7).

Considering each of two butane dimer model system (Fig. 6) separately, there are 360 energies (180 levels applied on two model systems). From these 360 energies, 41 have RMSD values less than $0.100 \mathrm{kcal} \mathrm{mol}^{-1}$, which is only about $11 \%$, significantly less than in case of 2-butene dimer (27\%) and 2-butene/butane systems (21\%) (Table S5 in Supporting Information). For each method we calculated 20 energies for two butane dimer model systems, using ten different basis sets for each method. The best method that gives calculated energies with almost all basis sets with the RMSD errors less than $0.100 \mathrm{kcal} \mathrm{mol}^{-1}$ is BLYP-D3BJ with 11 from 20 energies (55\%), followed by TPSS-D3BJ with 10 energies (50\%), and the next method B2PLYP-D3BJ, has only 5 energies (25\%) with error less than $0.100 \mathrm{kcal} \mathrm{mol}^{-1}$. There are 13 from 18 methods that have less than $10 \%$ of RMSD values below $0.100 \mathrm{kcal} \mathrm{mol}^{-1}$ and nine methods (50\%) that have none of RMSD values less $0.100 \mathrm{kcal} \mathrm{mol}^{-1}$.

Basis set has the highest influence on MP2 and M06 methods, and somewhat pronounced influence on B2PLYP, $\omega B 97 x D$,
M06HF and M052X. The increase of basis set size improves results with MP2 method (Fig. 7), similar to other studied systems (Figs. 3 and 5). The B2PLYP method with large basis sets overestimates interaction energies, while basis sets of intermediate size give the best results (Table 3), as was mentioned above. The M06-D3 method overestimate significantly energies with almost all basis sets, the largest error is for $6-311++\mathrm{G}^{* *}$ basis set, while the smallest errors are for the smallest basis sets. The M06HF-D3 method overestimates energies with $6-311++G^{* *}$ basis set and underestimates them with other basis sets, giving the smallest error for aug-ccpVDZ (Table 3) and 6-31G** basis sets (Fig. 7). The other DFT methods depend only slightly on basis sets and most of them overestimate interaction energies; only BP86-D3BJ significantly underestimate energies for butane dimer with parallel orientation (Supplementary Information S3) and TPSS-D3BJ method slightly underestimate energies for the same model system (Supplementary Information S3). Differently than in 2-butene dimer and in 2-butene/butane systems, one cannot notice that small basis sets give similar behavior with most of the used DFT methods.

\subsection{Overall benchmark}

The best ten levels overall, considering all model systems for (1) 2-butene dimers, (2) 2-butene/butane, and (3) butane dimes (Figs. 2, 4 and 6), are shown in Table 4. The data indicate that number of levels have the RMSD values below or close to $0.100 \mathrm{kcal} \mathrm{mol}^{-1}$ (Table S4 in Supporting Information). The best level is BLYP-D3BJ/def2-QZVP with RMSD error of $0.056 \mathrm{kcal} \mathrm{mol}^{-1}$, MARE of $1.8 \%$ and SD of $0.058 \mathrm{kcal} \mathrm{mol}^{-1}$. The four best levels are BLYP-D3BJ and PBE0-D3BJ with two large basis sets, def2-QZVP and cc-pVQZ. Table 4 also reveals that ten best levels of theory are with just several, quite large basis sets. Hence, one could make conclusion that in spite that most of the DFT methods do not show high dependence on basis set, and in spite that some calculated energies with small basis set are in good agreement with $\operatorname{CCSD}(\mathrm{T}) / \mathrm{CBS}$ values, large basis sets give the best results when all systems are considered together. Still one has to keep in mind, that the differences in calculated energies with smaller basis sets are very often not high.

For all model systems we calculated 1800 energies (18 methods, with ten basis sets for each method, used on ten model systems (Figs. 2, 4, and 6 and Table S4 in Supporting Information). From these 1800 energies, 487 energies (27\%) have RMSD errors below $0.100 \mathrm{kcal} \mathrm{mol}^{-1}$. With each method we used ten basis sets, and calculated energies for ten model systems, which is a total of 100 energies for each method. The best method overall is BLYPD3BJ with 61 energies (61\%) with errors less than $0.100 \mathrm{kcal} \mathrm{mol}^{-1}$, 


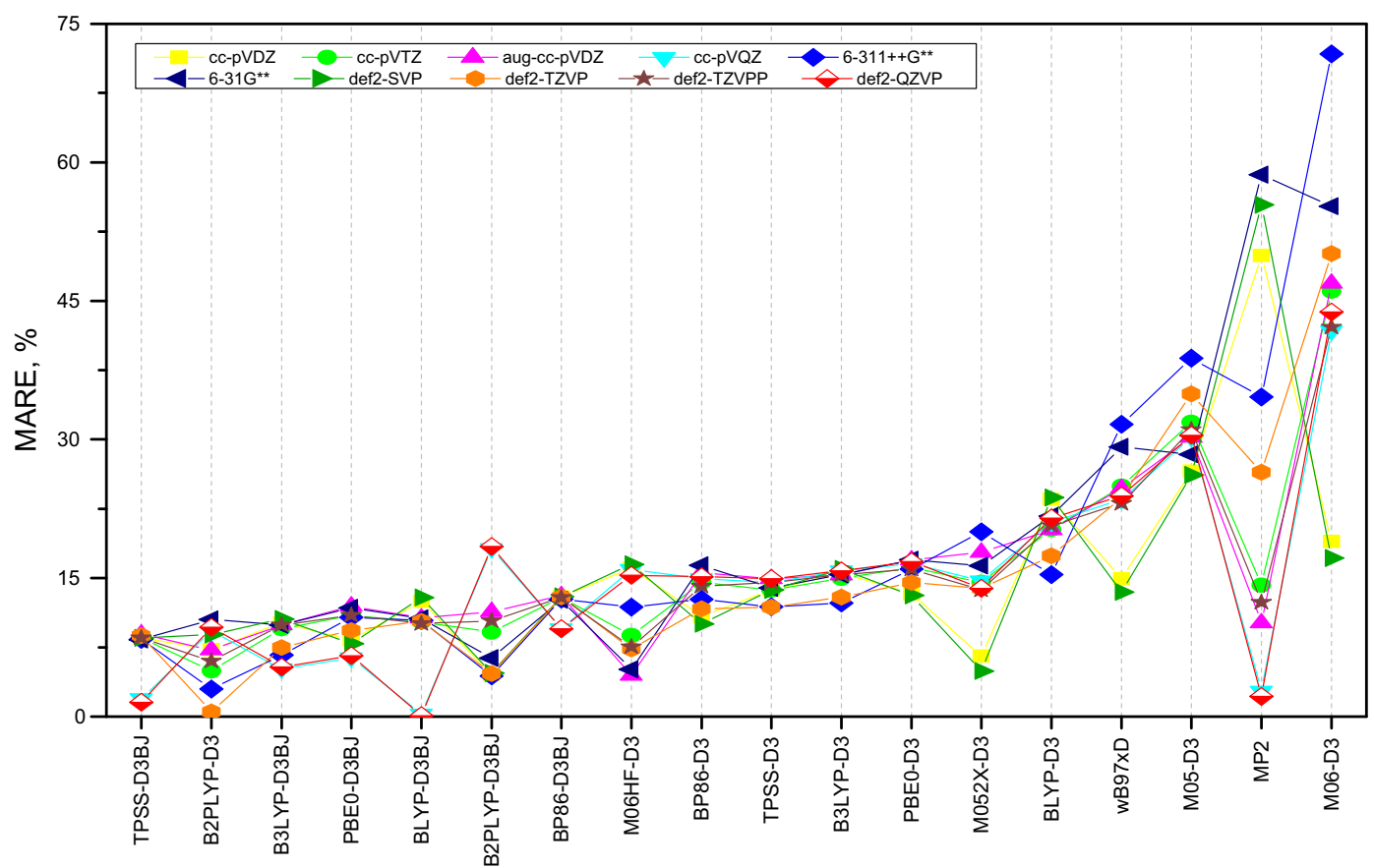

(a)

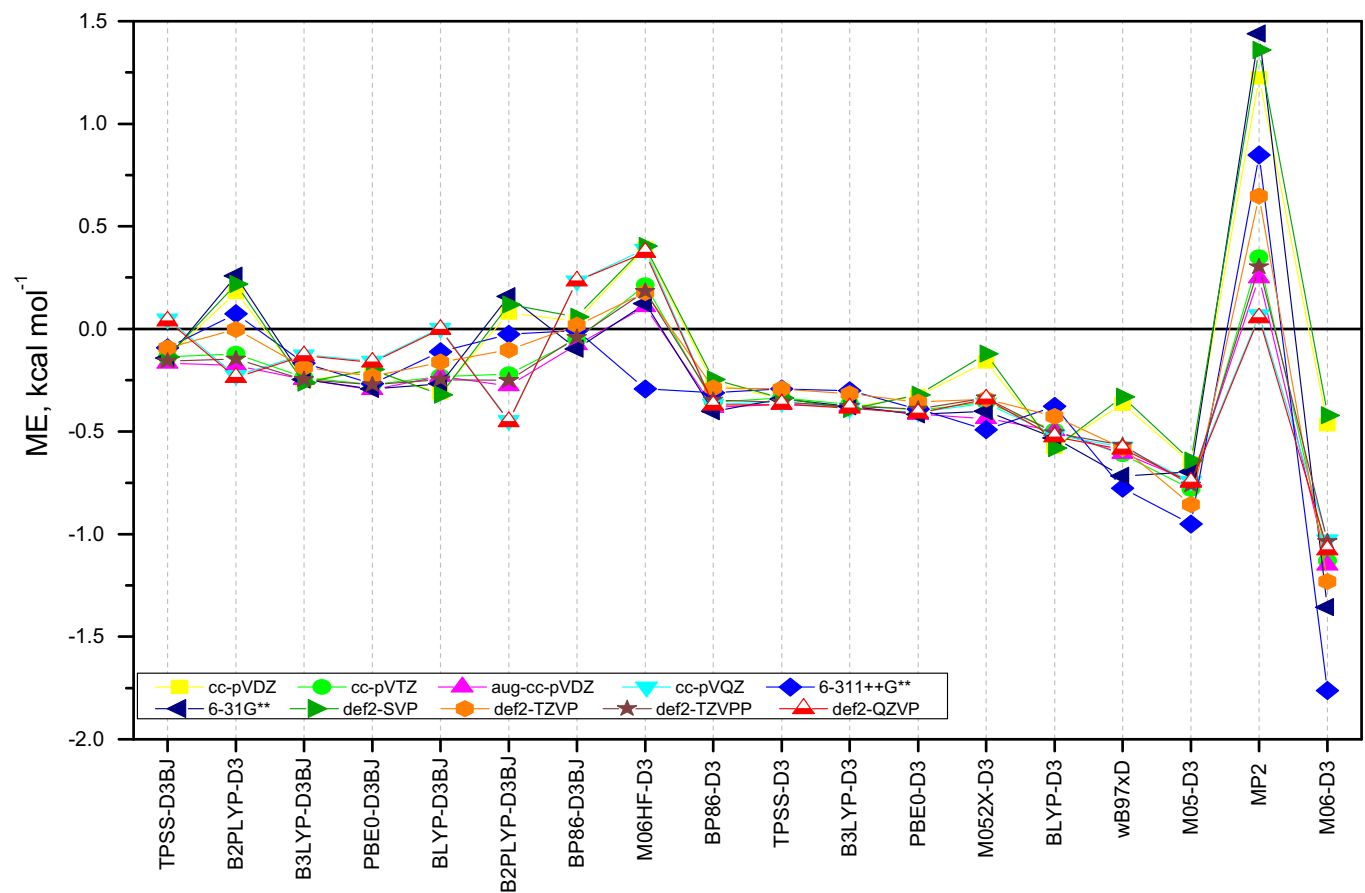

(b)

Fig. 7. (a) Mean Absolute Relative Error (MARE) [\%], (b) Mean Error (ME) [kcal mol ${ }^{-1}$ ] for butane dimer.

followed with B2PLYP-D3 method with 55 energies (55\%) with errors less than $0.100 \mathrm{kcal} \mathrm{mol}^{-1}$ (Table S4 in Supporting Information).

When the RMSD values are considered for interaction energies separately for (1) unsaturated/unsaturated systems (2-butene dimers), (2) unsaturated/saturated systems (2-butene/butane) and (3) saturated/saturated systems (butane dimers), as can be anticipated, smaller errors are obtained (Tables 1-3). One can notice that the best overall levels, BLYP-D3BJ/def2-QZVP and BLYP-D3BJ/cc-pVQZ, are not among best levels in model systems (1) 2-butene dimers or in (2) 2-butene/butane, but it is listed among the best levels in (3) butane dimers system. This is the consequence of the largest errors of almost all levels in (3) butane dimers system, hence the best methods for this system are the best methods overall.

The data in Tables 1-3, as well as data in Figs. 3, 5 and 7, indicate that used methods are better in reproducing interaction energies of unsaturated molecules, than saturated molecules. Also, the calculated interaction energies in saturated molecules are overestimated. In our previous work we obtained data on nature of the interactions in the same model systems using the SAPT analysis [30]. As was mentioned in the Introduction, the data show that 
Table 3

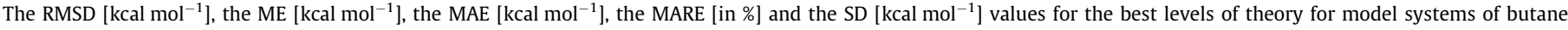
dimers.

\begin{tabular}{|c|c|c|c|c|c|c|c|}
\hline & Method & Basis set & RMSD & $\mathrm{ME}$ & MAE & MARE & SD \\
\hline 1 & BLYP-D3BJ & def2-QZVP & 0.0041 & -0.0016 & 0.0025 & 0.10 & 0.0035 \\
\hline 2 & BLYP-D3BJ & cc-pVQZ & 0.0087 & 0.0034 & 0.0075 & 0.31 & 0.011 \\
\hline 3 & B2PLYP-D3 & def2-TZVP & 0.016 & -0.0016 & 0.013 & 0.51 & 0.018 \\
\hline 4 & TPSS-D3BJ & def2-QZVP & 0.051 & 0.038 & 0.038 & 1.6 & 0.011 \\
\hline 5 & TPSS-D3BJ & cc-pVQZ & 0.063 & 0.048 & 0.048 & 2.0 & 0.011 \\
\hline 6 & MP2 & def2-QZVP & 0.072 & 0.053 & 0.053 & 2.2 & 0.018 \\
\hline 7 & MP2 & cc-pVQZ & 0.087 & 0.068 & 0.068 & 2.8 & 0.011 \\
\hline 8 & B2PLYP-D3 & $6-311++G^{* *}$ & 0.087 & 0.073 & 0.073 & 3.0 & 0.011 \\
\hline 9 & B2PLYP-D3BJ & cc-pVDZ & 0.14 & 0.078 & 0.11 & 4.5 & 0.16 \\
\hline 10 & M052X-D3 & def2-SVP & 0.14 & -0.12 & 0.12 & 4.9 & 0.039 \\
\hline
\end{tabular}

Table 4

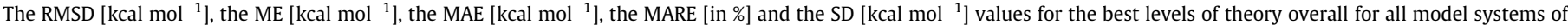
dimers, 2-butene/butane, and butane dimers studied in this work (Figs. 2, 4, 6).

\begin{tabular}{|c|c|c|c|c|c|c|c|}
\hline & Method & Basis set & RMSD & ME & MAE & MARE in \% & SD \\
\hline 1 & BLYP-D3BJ & def2-QZVP & 0.056 & -0.007 & 0.042 & 1.8 & 0.058 \\
\hline 2 & BLYP-D3BJ & cc-pVQZ & 0.060 & -0.012 & 0.049 & 2.1 & 0.061 \\
\hline 3 & PBE0-D3BJ & cc-pVQZ & 0.105 & -0.059 & 0.083 & 3.3 & 0.091 \\
\hline 4 & PBE0-D3BJ & def2-QZVP & 0.106 & -0.068 & 0.084 & 3.3 & 0.085 \\
\hline 5 & B2PLYP-D3 & aug-cc-pVDZ & 0.107 & -0.010 & 0.095 & 4.0 & 0.11 \\
\hline 6 & TPSS-D3BJ & def2-QZVP & 0.109 & 0.077 & 0.096 & 4.0 & 0.081 \\
\hline 7 & B2PLYP-D3 & def2-TZVPP & 0.109 & 0.010 & 0.099 & 4.2 & 0.11 \\
\hline 8 & B3LYP-D3BJ & def2-QZVP & 0.111 & -0.095 & 0.095 & 3.8 & 0.059 \\
\hline 9 & B3LYP-D3BJ & cc-pVQZ & 0.112 & -0.097 & 0.097 & 3.9 & 0.058 \\
\hline 10 & MP2 & cc-pVQZ & 0.115 & -0.074 & 0.102 & 4.4 & 0.092 \\
\hline
\end{tabular}

the most important attractive component is the dispersion, and the dispersion is the weakest in saturated butane dimer systems. This could indicate that the calculated dispersion corrections for butane dimers are overestimated, causing larger errors. However, the largest dispersion component was calculated for 2-butene/butane systems (larger than in 2-butene dimers), while the data in this work show that errors (and overestimation) of calculated energies are larger in 2-butene/butane systems than in 2-butene dimers. It would mean that, in spite that dispersion component is the largest in 2-butene/butane systems, correction is still overestimating it. On the other hand, since errors are the smallest in 2-butene dimers, one can assume that correction is the best adjusted to unsaturated molecules.

In order to examine closer influence of dispersion corrections, D3 zero damping and Becke-Johnson damping, we compared results for dispersion noncorrected, D3, and D3BJ corrected interaction energies for the three studied systems using def2-QZVP basis set, for several DFT methods used in our study. The ME values of the noncorrected, corrected D3 and corrected D3BJ are presented in Fig. 8. The data show, what is well known, that calculated interaction energies are underestimated (they are repulsive) without correction; while the energies with D3 corrections are close to the $\operatorname{CCSD}(\mathrm{T}) / \mathrm{CBS}$ values. However, most of the energies with D3 zero damping are overestimated, the calculated energies are too attractive. The overestimation is the smallest for 2-butene dimers, while it is up to $0.5 \mathrm{kcal} \mathrm{mol}^{-1}$ larger for systems (2) and (3) with saturated butane. The energies calculated with D3BJ correction are in better agreement with accurate energies, with a few exceptions. For B2PLYP method D3 correction gives better results for all three systems. One can notice that similar to D3 corrected energies, the agreement of D3BJ corrected energies is the best for systems with double bonds, 2-butene dimers. These results indicate that both corrections are better for interactions of unsaturated molecules, while the best results for alkanes are obtained with D3BJ correction. The data is represented in Table S6 in Supporting Information.

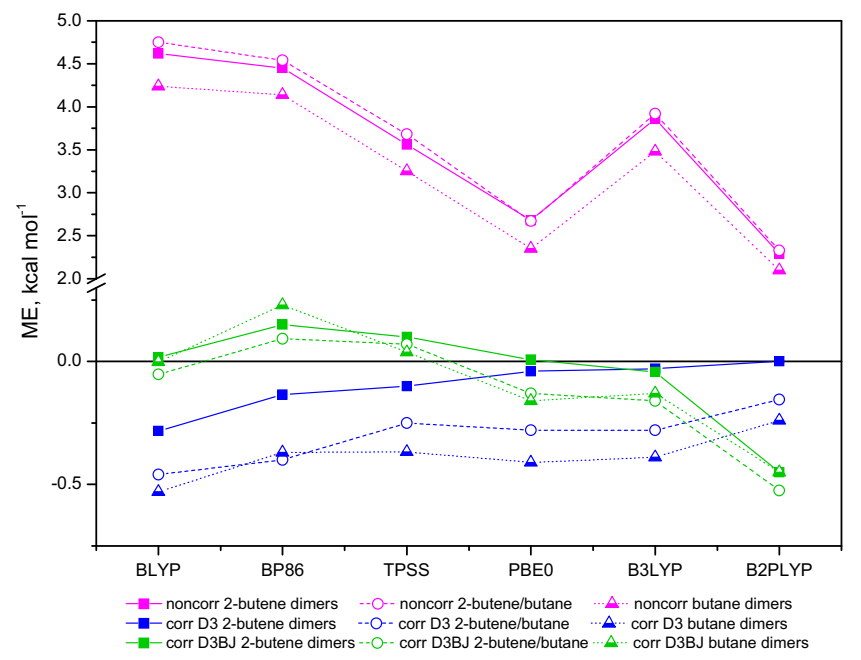

Fig. 8. Comparesment of the noncorrected, the D3 and the D3BJ dispersion corrected interaction energies for model systems of (1) 2-butene dimers, (2) 2 butene/butane, and (3) butane dimers. In all calculations def2-QZVP basis set was used.

\subsection{Potential curves}

On the 14th place from 1800 level of theory is the M052X-D3/ cc-pVDZ with the RMSD error of $0.120 \mathrm{kcal} \mathrm{mol}^{-1}$ (Supporting Information, Table S4). These data indicate that using the M052X-D3/cc-pVDZ level in our previous work [30] to calculate potential curves was quite reasonable. In this work we found that other methods give more accurate results. Hence, we recalculated potential energy surfaces using levels which are in the best agreement with the $\operatorname{CCSD}(\mathrm{T}) / \mathrm{CBS}$ at each group system (1) 2-butene dimers, (2) 2-butene/butane and (3) butane dimers. For (1) 2-butene dimers B3LYP-D3BJ/aug-cc-pVDZ was used, for (2) 
2-butene/butane BLYP-D3BJ/def2-SVP and for (3) butane dimers BLYP-D3BJ/def2-QZVP level was used. The potential curves were calculated, as in the previous work, examining the interaction energies as a function of the horizontal displacements (offsets, $r$ ) by varying the normal distance $(R)$ between the two molecules (Fig. 1 ) in a single point series calculations, while the geometries of the monomers were kept rigid. The offset values, $r$, of $-3.0 \AA$ to $+3.0 \AA$ with step of $0.2 \AA$ were used for calculating energies. For simplicity, the potential energy surfaces are shown as curves, presenting the energies for optimal normal distances, $R$ (Fig. 9). The optimal normal distances in function of offset values are given in Supporting Information, Figs. S4-S9. Table 5 presents the data on potential curves minima. The potential curves minima geometries were fully optimized and optimized geometries are presented in Supporting Information (Fig. S1-3).

The new potential curves have similar shapes as previously obtained at M052X-D3/cc-pVDZ level [30]. New curves for systems (1) 2-butene dimers show stronger energies for almost all offset values (Fig. 9a-c), whereas curves for interactions of saturated butane in (2) 2-butene/butane and in (3) butane dimer show less strong energies (Fig. 9d-f). It can be anticipated, because the M052X-D3/cc-pVDZ level overestimates interactions in (2) 2-butene/butane and in (3) butane dimer systems (Figs. 5 and 7 ).

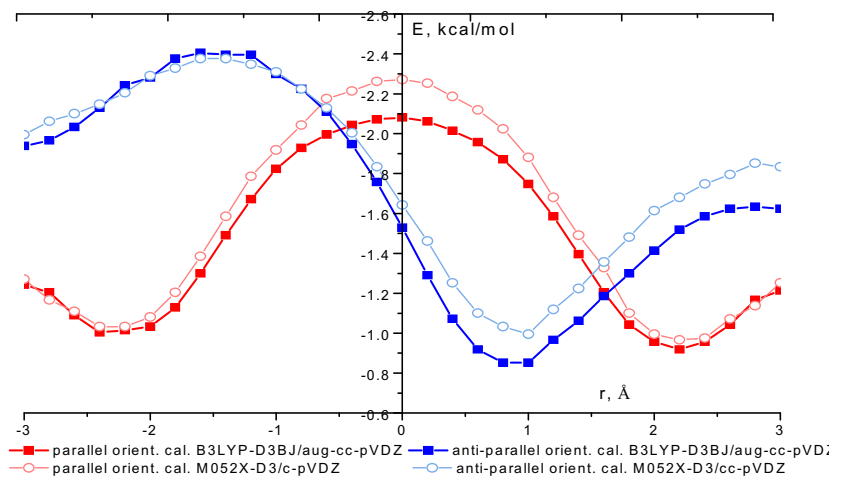

(a) cis-2-butene dimers

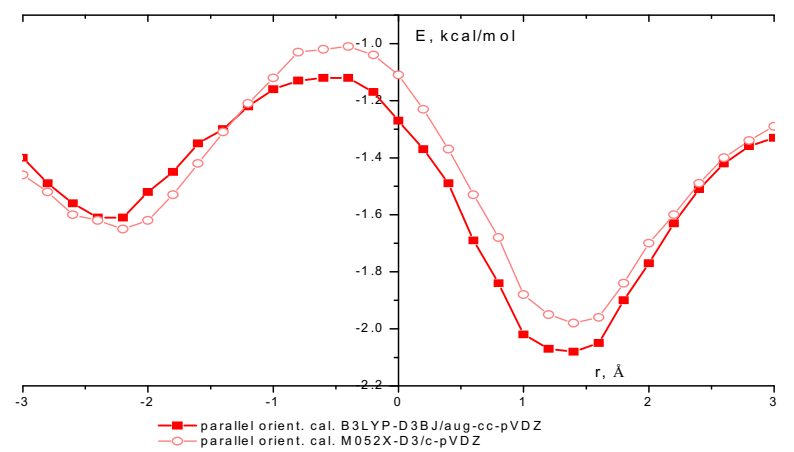

(c) cis-2-butene / trans-2-butene

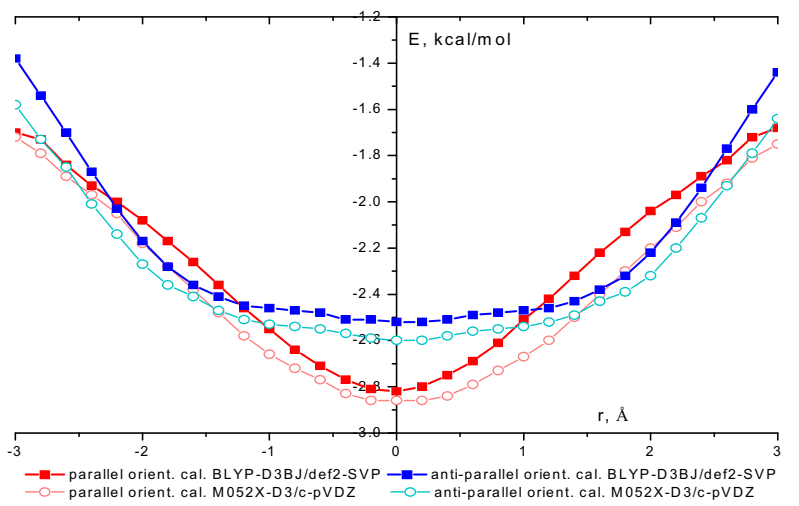

(e) trans-2-butene / butane

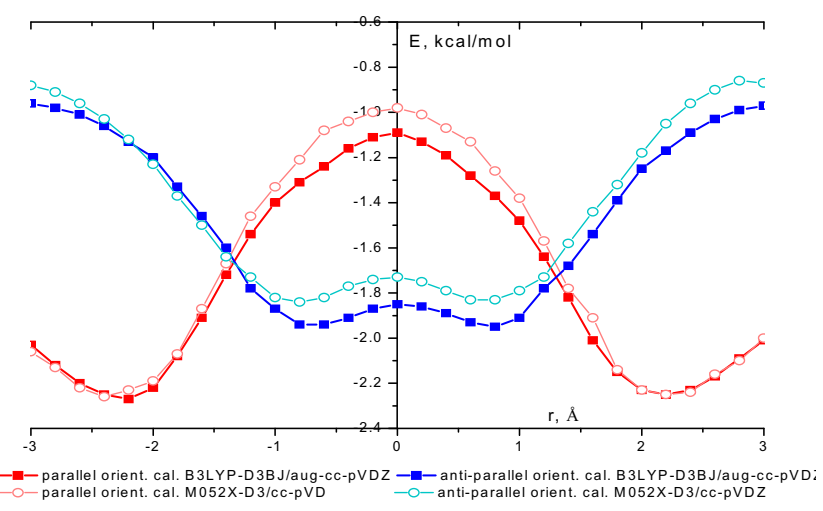

(b) trans-2-butene

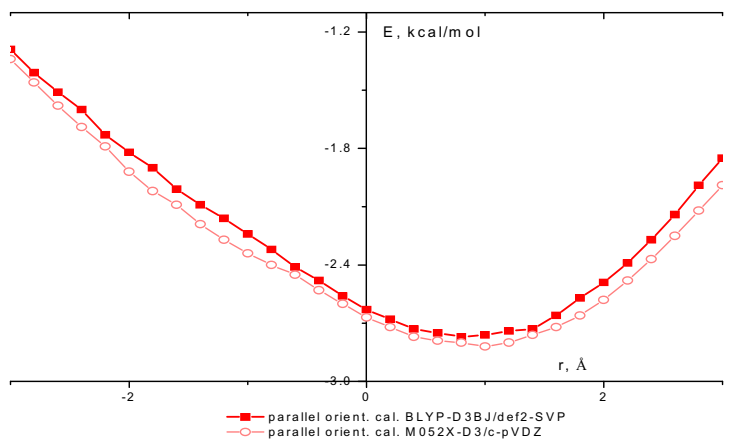

(d) cis-2-butene / butane

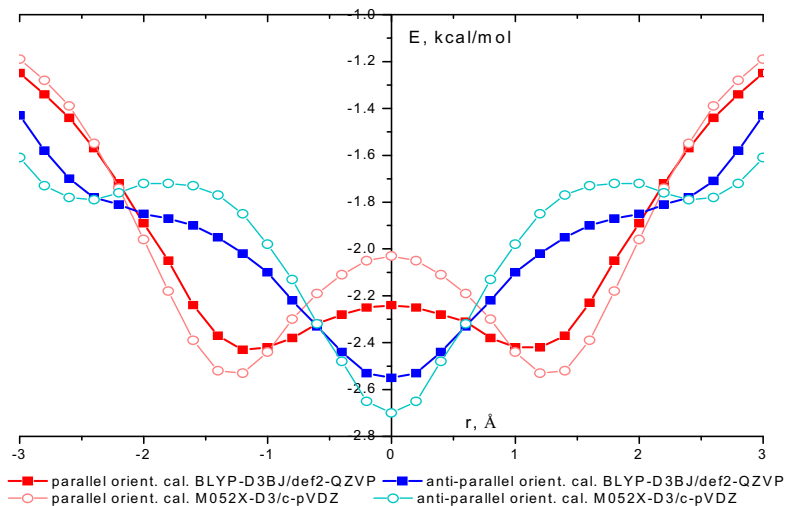

(f) butane dimers

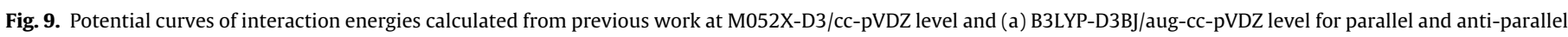

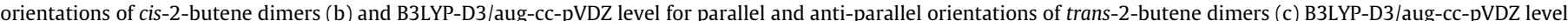

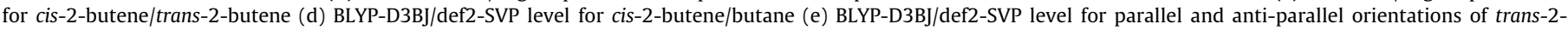
butene/butane (f) BLYP-D3BJ/def2-QZVP level for parallel and anti-parallel orientations of butane dimers. 
Table 5

Geometric data for minima on potential curves and energies of interactions for each model system.

\begin{tabular}{|c|c|c|c|c|c|c|c|c|c|c|}
\hline & \multicolumn{2}{|l|}{$r[\AA]$} & \multicolumn{2}{|l|}{$\mathrm{R}[\AA]$} & \multicolumn{2}{|c|}{$\Delta$ Emin $\left[\mathrm{kcal} \mathrm{mol}^{-1}\right]$} & \multicolumn{2}{|c|}{$\Delta$ Eopt $\left[\mathrm{kcal} \mathrm{mol}^{-1}\right]$} & \multicolumn{2}{|c|}{$\begin{array}{l}\Delta \mathrm{E}(\mathrm{CCSD}(\mathrm{T}) / \mathrm{CBS}) \\
{\left[\mathrm{kcal} \mathrm{mol}^{-1}\right]}\end{array}$} \\
\hline & Previous $^{\mathrm{a}}$ & $\begin{array}{l}\text { This } \\
\text { work }^{\mathrm{b}}\end{array}$ & Previous $^{\mathrm{a}}$ & $\begin{array}{l}\text { This } \\
\text { work }^{\mathrm{b}}\end{array}$ & Previous $^{\mathrm{a}}$ & $\begin{array}{l}\text { This } \\
\text { work }^{\mathrm{b}}\end{array}$ & Previous $^{\mathrm{a}}$ & $\begin{array}{l}\text { This } \\
\text { work }^{\mathrm{b}}\end{array}$ & Previous $^{\mathrm{a}}$ & $\begin{array}{l}\text { This } \\
\text { work }^{\mathrm{b}}\end{array}$ \\
\hline \multicolumn{11}{|l|}{ (1) 2-Butene dimers } \\
\hline Parallel orientation of cis-2-butene dimer & 2.4 & 2.2 & 3.3 & 3.3 & -2.32 & -2.37 & -2.41 & -2.44 & -2.32 & -2.36 \\
\hline $\begin{array}{l}\text { Anti-parallel orientation of cis-2-butene } \\
\text { dimer }\end{array}$ & 1.0 & 0.9 & 3.7 & 3.6 & -2.29 & -2.49 & -2.30 & -2.49 & -2.48 & -2.53 \\
\hline Parallel orientation of trans-2-butene dimer & 2.3 & 2.2 & 3.3 & 3.3 & -2.26 & -2.27 & -2.68 & -2.65 & -2.29 & -2.29 \\
\hline $\begin{array}{l}\text { Anti-parallel orientation of trans-2-butene } \\
\quad \text { dimer }\end{array}$ & 0.8 & 0.8 & 3.6 & 3.6 & -1.84 & -1.95 & -2.52 & -2.54 & -1.95 & -1.95 \\
\hline cis-2-butene/trans-2-butene & 1.3 & 1.4 & 3.7 & 3.7 & -1.98 & -2.14 & -2.78 & -2.93 & -2.13 & -2.15 \\
\hline \multicolumn{11}{|l|}{ (2) 2-butene/butane } \\
\hline cis-2-butene/butane & 1.0 & 0.8 & 3.8 & 3.8 & -2.82 & -2.77 & -3.19 & -2.90 & -2.73 & -2.74 \\
\hline $\begin{array}{l}\text { Parallel orientation of trans-2-butene/ } \\
\text { butane }\end{array}$ & 0.2 & 0.0 & 3.8 & 3.8 & -2.86 & -2.82 & -3.26 & -2.94 & -2.80 & -2.82 \\
\hline $\begin{array}{l}\text { Anti-parallel orientation of trans-2-butene/ } \\
\text { butane }\end{array}$ & 0.2 & 0.0 & 3.8 & 3.8 & -2.60 & -2.52 & -2.78 & -2.53 & -2.49 & -2.50 \\
\hline \multicolumn{11}{|l|}{ (3) Butane dimers } \\
\hline Parallel orientation of butane dimer & 1.2 & 1.2 & 4.0 & 3.9 & -2.53 & -2.43 & -2.74 & -2.59 & -2.40 & -2.44 \\
\hline Anti-parallel orientation of butane dimer & 0.0 & 0.0 & 4.0 & 3.9 & -2.70 & -2.55 & -2.74 & -2.54 & -2.51 & -2.58 \\
\hline
\end{tabular}

[a] Calculated at M052X-D3/cc-pVDZ level.

[b] Calculated at this work:

(1) 2-Butene dimers at B3LYP-D3BJ/aug-cc-pVDZ level.

(2) 2-Butene/butane at BLYP-D3BJ/def2-SVP level.

(3) Butane dimers at BLYP-D3BJ/def2-QZVP level.

Data in Table 5 indicate that geometries on the potential curves minima are very similar in this and in previous work [30], with some small differences. Calculated energies at minima using M052X-D3/ cc-pVDZ level in previous work and B3LYP-D3BJ/aug-cc-pVDZ, BLYP-D3BJ/def2-SVP, and BLYP-D3BJ/def2-QZVP levels in this work, show some differences with the same trend that one can observe from potential curves in Fig. 9. Namely, energies calculated in this work for 2-butene dimer are somewhat stronger, while energies for 2-butene/butane and butane dimers are less strong (Table 5). The largest differences were observed for 2-butene dimers and for butane dimer; for the anti-parallel orientation of cis-2-butene dimer and for cis-2-butene/trans-2-butene the new energies are stronger for 0.20 and $0.16 \mathrm{kcal} \mathrm{mol}^{-1}$, respectively, while for anti-parallel orientation of butane dimer the energy is weaker for $0.15 \mathrm{kcal} \mathrm{mol}^{-1}$, making relative differences between two model systems as high as $0.35 \mathrm{kcal} \mathrm{mol}^{-1}$, what is approximately $15 \%$ of calculated interaction energies. For optimized geometries, the differences between previous and new interaction energies are even larger, for several systems differences are $0.20 \mathrm{kcal} \mathrm{mol}^{-1}$, while the largest difference is for parallel orientation of trans-2-butene/butane; the new energy is less strong for $0.32 \mathrm{kcal} \mathrm{mol}^{-1}$ (Table 5).

The data in Table 5 present also values of $\operatorname{CCSD}(\mathrm{T}) / \mathrm{CBS}$ energies calculated by using geometries of minima at potential curves obtained in previous and in this work. The data show that energies calculated in previous work are similar with energies calculated in this work, the differences are less than $0.10 \mathrm{kcal} \mathrm{mol}^{-1}$. The new energies are somewhat stronger for several model systems, since better methods used for calculations in this work give somewhat better geometries. The largest difference is observed for antiparallel butane dimers, the energy calculated in this work is $0.070 \mathrm{kcal} \mathrm{mol}^{-1}$ stronger (Table 5).

The $\operatorname{CCSD}(\mathrm{T}) / \mathrm{CBS}$ interacting energies calculated in this work on, in some cases better geometries, show, as well as energies from previous work, that the interactions in the 2-butene/butane systems are the strongest. Also in agreement with previous work, the model system of parallel trans-2-butene/butane has the strongest interaction, while trans-2-butene dimer has the weakest interaction (Table 5).

\section{Conclusions}

Benchmark study for interactions in (1) unsaturated/unsaturated systems (2-butene dimers), (2) unsaturated/saturated system (between 2-butene and butane) and (3) saturated/saturated (butane dimers) was performed. In the study interaction energies calculated by 18 methods, with ten different basis sets for each of the method, were compared with accurate $\operatorname{CCSD}(\mathrm{T}) / \mathrm{CBS}$ energies. The results indicate that most of the methods, with all basis sets, have largest errors for systems with saturated bonds, butane dimers. Also most of the methods overestimate interaction energies in systems with butane. The overall best levels are BLYPD3BJ/def2-QZVP and the BLYP-D3BJ/cc-pVQZ with similar RMSD values of $0.056 \mathrm{kcal} \mathrm{mol}^{-1}$ and $0.060 \mathrm{kcal} \mathrm{mol}^{-1}$, whereas the next several levels are also close with errors less than $0.11 \mathrm{kcal} \mathrm{mol}^{-1}$.

The best level for (1) 2-butene dimers is B3LYP-D3BJ/aug-ccpVDZ with RMSD value of $0.020 \mathrm{kcal} \mathrm{mol}^{-1}$, for (2) interactions between 2-butene and butane is BLYP-D3BJ/def2-SVP with RMSD value of $0.023 \mathrm{kcal} \mathrm{mol}^{-1}$, whereas for (3) butane dimer is BLYPD3/def2-QZVP with RMSD value of $0.004 \mathrm{kcal} \mathrm{mol}^{-1}$. However, number of the theory levels show similar accuracy, with the RMSD values below $0.100 \mathrm{kcal} \mathrm{mol}^{-1}$. The potential surfaces were calculated with a method that is the best for each model system (1), (2), and (3). These potential surfaces are similar with potential surfaces calculated in previous work at M052X-D3/cc-pVDZ level, with the difference in the calculated energies on the new and previous curves of as much as $0.2 \mathrm{kcal} \mathrm{mol}^{-1}$. The values of $\operatorname{CCSD}(\mathrm{T}) /$ CBS calculated for minima on potential surfaces are for several model systems somewhat stronger than calculated previously [30].

The results on different methods show that although difference in calculated energies among several methods are not high, the comparison of strength in 2-butene dimers with strength in butane dimers can show significant differences, as some of the methods underestimate strength of interactions in 2-butene dimers while overestimating it in butane dimers. Hence, generally, one should be careful in choosing DFT method, which is good for systems with double bonds, and systems with single bonds, since interaction energies in saturated systems can be significantly overestimated. 
In our future work we will study properties and interactions of systems with double and single bonds, hence, these results are important for our future studies that will combine experimental data on mixtures with calculations on interactions in the mixtures.

\section{Acknowledgments}

The authors are grateful to Ministry of Education, Science and Technology Development, Republic of Serbia for the support, Projects no. OI172063 and III46010.

\section{Appendix A. Supplementary material}

Supplementary data associated with this article can be found, in the online version, at http://dx.doi.org/10.1016/j.comptc.2017.08. 001.

\section{References}

[1] L.M. Salonen, M. Ellermann, F. Diederich, Angew. Chem. Int. Ed. 50 (2011) 4808-4842H;

J. Schneider, Acc. Chem. Res. 46 (2013) 1010-1019;

C.J. Janiak, J. Chem. Soc., Dalton. Trans. 21 (2000) 3885-3896;

C. Estarellas, A. Frontera, D. Quinonero, P.M. Deya, Comp. Theor. Chem. 975 (2011) 106-110.

[2] B. Kelly, G. Sanchez-Sanz, F. Blanco, Comp. Theor. Chem. 998 (2012) 64-73.

[3] C.R. Martinez, B.L. Iverson, Chem. Sci. 3 (2012) 2191-2201;

Y. Cho, W.J. Cho, I.S. Youn, G. Lee, N.J. Singh, K.S. Kim, Acc. Chem. Res. 47 (2014) 3321-3330;

G. Shi, J. Yang, Y. Ding, H. Fang, Chem. Phys. Chem. 15 (2014) 2588-2594;

N.W. Ulrich, N.A. Seifert, R.E. Dorris, A.R. Peebles, B.H. Pate, S.A. Peeble, Phys. Chem. Chem. Phys. 16 (2014) 8886-8894.

[4] D. Quinonero, A. Frontera, P.M. Deya, Comp. Theor. Chem. 998 (2012) 51-56.

[5] E.R.T. Tiekink, J. Zukerman-Schpector, Cryst. Eng. Commun. 11 (2009) 11761186 ;

M. Gao, X. Yang, J. Cheng, Q. Li, W. Li, R.E. Loffredo, Chem. Phys. Chem. 14 (2013) 3341-3347.

[6] A. Forni, S. Pieraccini, S. Rendine, F. Gabas, M.H. Sironi, Chem. Phys. Chem. 13 (2012) 4224-4234;

J. Hooper, V.R. Cooper, T. Thonhauser, N.A. Romero, F. Zerilli, D.C. Langreth, Chem. Phys. Chem. 9 (2008) 891-895;

C. Elschenbroich, B. Kanellakopulos, F.H. Koehler, B. Metz, R. Lescoueezec, N.W. Mitzel, W. Strauss, Chem. Eur. J. 13 (2007) 1191-1200.

[7] R. Anez, A. Sierraalta, D. Coll, O. Castellanos, H. Soscun, Comp. Theor. Chem 1084 (2016) 133-139.

[8] M.O. Sinnokrot, C.D. Sherrill, J. Phys. Chem. A 110 (2006) 10656-10668; R. Podeszwa, R. Bukowski, K. Szalewicz, J. Phys. Chem. A 110 (2006) 10345 10354;

M. Pitonak, P. Neogrady, J. Rezac, P. Jurecka, M. Urban, P. Hobza, J. Chem. Theory. Comput 4 (2008) 1829-1834;

T. Janowski, P. Pulay, Chem. Phys. Lett. 447 (2007) 27-32;

M. Rapacioli, F. Spiegelman, D. Talbi, T. Mineva, A. Gourso, T. Heine, G. Seifert, J Chem. Phys. 130 (2009) 244304

[9] J. Rezač, K.E. Riley, P. Hobza, J. Chem. Theory Comput. 7 (2011) 2427-2438.

[10] D. Mikulski, K. Eder, M. Molski, Comp. Theor. Chem. 1046 (2014) 118-125.

[11] S. Boehm, O. Exner, J. Mol. Struct. THEOCHEM 682 (2004) 171-177.

[12] Y. Cao, M.W. Wong, J. Mol. Model. 20 (2014) 2185.

[13] Y.N. Kalugina, V.N. Cherepanov, M.A. Buldakov, N. Zvereva-Loëte, V. Boudon, J. Comput. Chem. 33 (2012) 319-330.

[14] S. Tsuzuki, T. Uchimaru, K. Tanabe, Chem. Phys. Lett. 287 (1998) 202-208.

[15] A. Gloß, M.P. Braendle, W. Klopper, H.P. Luethi, Mol. Phys. 110 (2012) $2523-$ 2534.

[16] K.S. Kim, S. Karthikeyan, N.J. Singh, J. Chem. Theory. Comput. 7 (2011) 34713477.

[17] I.L. Alberts, T.W. Rowlands, N.C. Handy, J. Phys. Chem. 88 (1988) 3811-3816.

[18] S. Tsuzuki, K. Tanabe, J. Phys. Chem. 96 (1992) 10805-10808.

[19] R.A. King, Mol. Phys. 107 (2009) 789-795.

[20] S. Tsuzuki, T. Uchimaru, M. Mikami, K. Tanabe, Chem. Phys. Lett. 252 (1996) 206-210.

[21] J. Pittner, P. Hobza, Chem. Phys. Lett. 390 (2004) 496-499.

[22] P. Rubio-Pereda, N. Takeuchi, J. Mol. Model. 22 (2016) 175.

[23] P. Cysewski, B. Szefler, J. Mol. Model. 16 (2010) 1709-1720.

[24] W. Gao, D. Cui, J. Am. Chem. Soc. 130 (2008) 4984-4991; B. Wang, D. Cui, K. Lv, Macromolecules 41 (2008) 1983-1988; D. Gong, W. Liu, W. Pan, T. Chen, X. Jia, K.W. Huang, X. Zhang, J. Mol. Catal. A: Chem. 406 (2015) 78-84.
[25] G.C. Blytas, Separation and Purification Technology, Marcel Dekker, New York, 1992;

K. Wang, E.I. Stiefel, Science 291 (2001) 106-109;

Y. Fan, M.B. Hall, J. Am. Chem. Soc. 124 (2002) 12076-12077.

[26] A.B. Knezević-Stevanović, S.P. Šerbanović, I.R. Radović, B.D. Djordjević, M. Lj, Kijevčani, J. Chem. Eng. Dat. 58 (2013) 2932-2951;

V.D. Spasojević, B.D. Djordjević, S.P. Šerbanović, I.R. Radović, M. Lj, Kijevčani, J. Chem. Eng. Data 59 (2014) 1817-1829.

[27] S. Moncho, E.N. Brothers, M.B. Hall, J. Mol. Model. 21 (2015) 107.

[28] M.B. Katan, P.L. Zock, R.P. Mensink, Annu. Rev. Nutr. 15 (1995) 473-493; R.R. Mensink, P.L. Zock, M.B. Katan, G. Hornstra, J. Lipid. Res. 33 (1992) 14931501;

D. Kromhout, A. Menotti, B. Bloemberg, C. Aravanis, H. Blackburn, R. Buzina, A. Dontas, F. Fidanza, S. Giampaoli, A. Janse, Prev. Med. 24 (1995) 308-315; S. Simonetti, M. Martirena, S. Ulacco, G. Brizuela, Appl. Surf. Sci. 264 (2013) 305-311.

[29] I. Cukrowski, F. Sagan, M.P. Mitoraj, J. Comp. Chem. 37 (2016) 2783-2798.

[30] M.M. Zarić, B. Bugarski, M.Lj. Kijevčanin, Chem. Phys. Chem. 17 (2016) 317324.

[31] B. Jeziorski, R. Moszynski, K. Szalewicz, Chem. Rev. 7 (1994) 1887-1930; J. Hoja, A.F. Sax, K. Szalewicz, Chem. Eur. J. 20 (2014) 2292-2300; E.G. Hohenstein, C.D. Sherrill, Comput. Mol. Sci. 2 (2012) 304-326; T.M. Parker, L.A. Burns, R.M. Parrish, A.G. Ryno, C.D. Sherrill, J. Chem. Phys. 140 (2014) 094106-94111.

[32] A. Li, H.S. Muddana, M.K. Gilson, J. Chem. Theory Comput. 10 (2014) 15631575.

[33] L. Rojas, F. Ruette, A. Peraza, O. Castellano, H. Soscún, Chem. Phys. Lett. 625 (2015) 20-25.

[34] L. Ferrighi, G.K.H. Madsen, B. Hammer, Chem. Phys. Lett. 492 (2010) 183-186.

[35] G. Paytakov, T. Dinadayalane, J. Leszczynski, J. Phys. Chem. A 119 (2015) 11901200.

[36] S. Tsuzuki, K. Honda, T. Uchimaru, M. Mikami, J. Chem. Phys. 124 (2006) 114304

[37] M.J. Frisch, G.W. Trucks, H.B. Schlegel, G.E. Scuseria, M.A. Robb, J.R. Cheeseman, G. Scalmani, V. Barone, B. Mennucci, G.A. Petersson, H. Nakatsuji, M. Caricat, X. Li, H.P. Hratchian, A.F. Izmaylov, J. Bloino, G. Zheng, J.L. Sonnenberg, M. Hada, M. Ehara, K. Toyota, R. Fukuda, J. Hasegawa, M. Ishida, T. Nakajima, Y. Honda, O. Kitao, H. Nakai, T. Vreven, J.A. Montgomery, Jr., J.E. Peralta, F. Ogliaro, M. Bearpark, J.J. Heyd, E. Brothers, K.N. Kudin, V.N. Staroverov, R. Kobayashi, J. Normand, K. Raghavachari, A. Rendell, J.C. Burant, S.S. Iyengar, J. Tomasi, M. Cossi, N. Rega, J.M. Millam, M. Klene, J.E. Knox, J.B. Cross, V. Bakken, C. Adamo, J. Jaramillo, R. Gomperts, R.E. Stratmann, O. Yazyev, A.J. Austin, R. Cammi, C. Pomelli, J.W. Ochterski, R.L. Martin, K. Morokuma, V.G. Zakrzewski, G.A. Voth, P. Salvador, J.J. Dannenberg, S. Dapprich, A.D. Daniels, O. Farkas, J.B. Foresman, J.V. Ortiz, J. Cioslowski, D.J. Fox, Gaussian 09 (Revision D.01), Gaussian, Inc., Wallingford, CT, 2013.

[38] C. Møller, M.S. Plesset, Phys. Rev, 46 (1934) 618-622.

[39] B. Miehlich, A. Savin, H. Stoll, H. Preuss, Chem. Phys. Lett. 157 (1989) 200-206; C. Lee, W. Yang, G. Parr, Phys. Rev. B. 37 (1988) 785.

[40] A.D. Becke, Phys. Rev. A 38 (1988) 3098-3100;

J.P. Perdew, Phys. Rev. B. Condens. Matter. 33 (1986) 8822-8824; J.P. Perdew, Phys. Rev. B. Condens. Matter. 34 (1986) 7406.

[41] Y. Zhao, N.E. Schultz, D.G. Truhlar, J. Chem. Phys. 123 (2005) 161103.

[42] Y. Zhao, N.E. Schultz, D.G. Truhlar, J. Chem. Theory Comput. 2 (2006) 364-382.

[43] Y. Zhao, D.G. Truhlar, Theor. Chem. Acc. 120 (2008) 215-241.

[44] Y. Zhao, D.G. Truhlar, J. Phys. Chem. A. 110 (2006) 5121-5129; Y. Zhao, D.G. Truhlar, J. Phys. Chem. A. 110 (2006) 13126-13130.

[45] J.M. Tao, J.P. Perdew, V.N. Staroverov, G.E. Scuseria, Phys. Rev. Lett. 91 (2003) 146401.

[46] J.P. Perdew, K. Burke, M. Ernzerhof, Phys. Rev. Lett. 77 (1996) 3865-3868; J.P. Perdew, K. Burke, M. Ernzerhof, Phys. Rev. Lett. 78 (1997) 1396.

[47] A.D. Becke, J. Chem. Phys. 98 (1993) 5648-5652; B. Miehlich, A. Savin, H. Stoll, H. Preuss, Chem. Phys. Lett. 157 (1989) 200-206; C. Lee, W. Yang, G. Parr, Phys. Rev. B. 37 (1988) 785;

P.J. Stephens, F.J. Devlin, C.F. Chabalowski, J. Phys. Chem. 98 (1994) $11623-$ 11627.

[48] L. Goerigk, S. Grimme, J. Chem. Theory Comput. 7 (2011) 291-309.

[49] J.D. Chai, M. Head-Gordon, Phys. Chem. Chem. Phys. 10 (2008) 6615-6620.

[50] T.H. Dunning Jr., J. Chem. Phys. 90 (1989) 1007-1023.

[51] R.A. Kendall, T.H. Dunning Jr, R.J. Harrison, J. Chem. Phys. 96 (1992) 67966806.

[52] D.E. Woon, T.H. Dunning Jr., J. Chem. Phys. 98 (1993) 1358-1371.

[53] F. Weigend, R. Ahlrichs, Phys. Chem. Chem. Phys. 7 (2005) 3297-3305.

[54] G.A. Petersson, A. Bennett, T.G. Tensfeldt, M.A. Al-Laham, W.A. Shirley, J. Mantzaris, J. Chem. Phys. 89 (1988) 2193-2218; G.A. Petersson, M.A. Al-Laham, J. Chem. Phys. 94 (1991) 6081-6090.

[55] R. Krishnan, J.S. Binkley, R. Seeger, J.A. Pople, J. Chem. Phys. 72 (1980) 650-654.

[56] S. Grimme, J. Antony, S. Ehrlich, H. Krieg, J. Chem. Phys. 132 (2010) 154104.

[57] S. Grimme, S. Ehrlich, L. Goerigk, J. Comp. Chem. 32 (2011) 1456-1465.

[58] W. Hujo, S. Grimme, Phys. Chem. Chem. Phys. 13 (2011) 13942-13950.

[59] S.F. Boys, F. Bernardi, Mol. Phys. 19 (1970) 553-566.

[60] I.D. Mackie, G.A. DiLabio, J. Chem. Phys. 135 (2011) 134318. 